
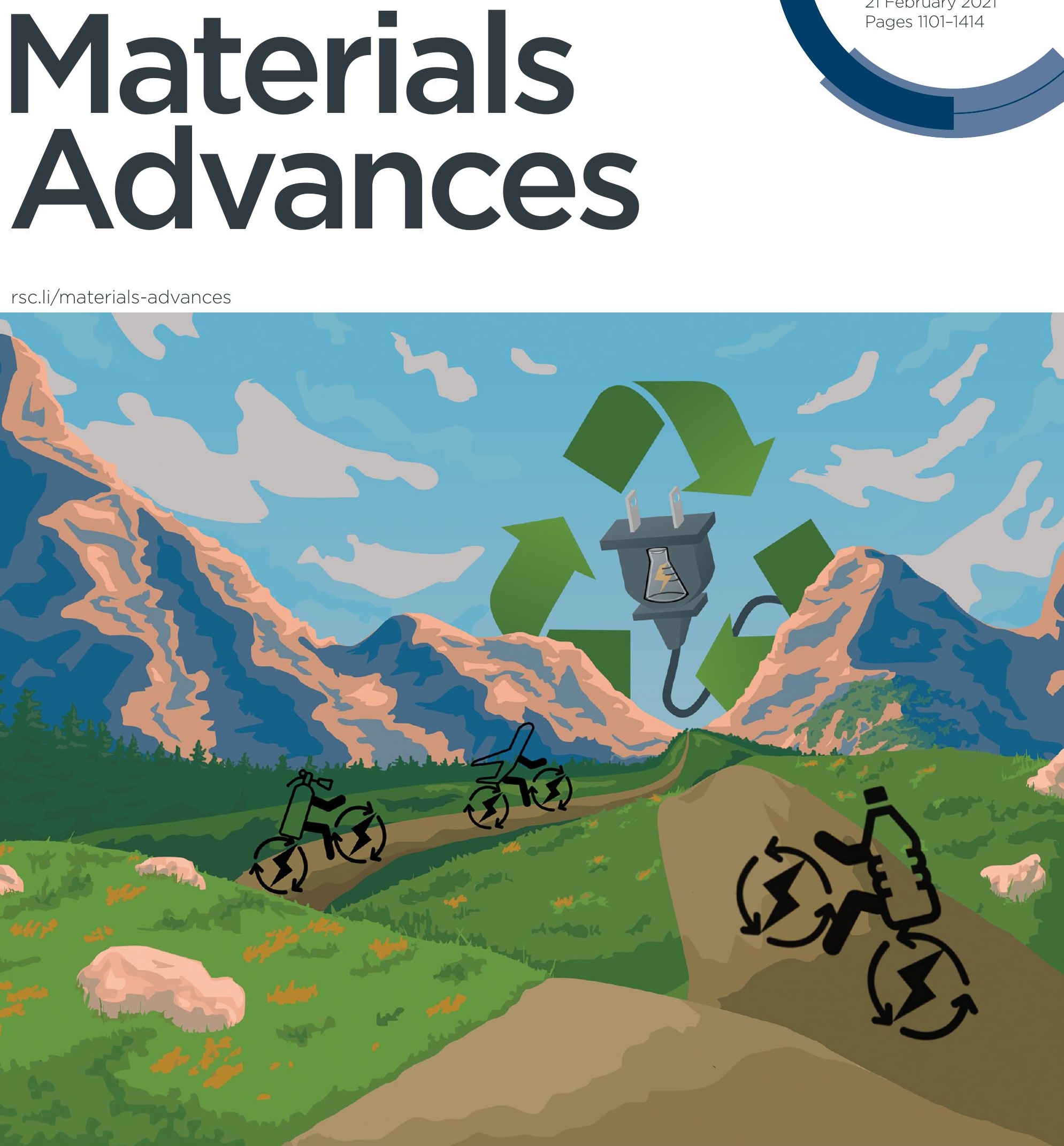
Check for updates

Cite this: Mater. Adv., 2021, 2, 1113

Received 8th September 2020, Accepted 2nd January 2021

DOI: 10.1039/d0ma00689k

rsc.li/materials-advances

\section{Electrochemical methods for materials recycling}

\author{
Haley A. Petersen, (D) † Tessa H. T. Myren, (D) † Shea J. O'Sullivan (D) and \\ Oana R. Luca (D)*
}

\begin{abstract}
The present review describes electrochemical methods for the recovery of chemical feedstocks from waste materials. We emphasize the use of electrical current, fields, and controlled potentials as sustainable, scalable solutions to impending societal challenges such as materials recycling and the management of solid wastes. This review focuses on two facets of electrochemical recycling: (1) the recovery of critical raw materials from wastes that would otherwise be destined for landfills and (2) the recycling and upcycling of waste polymer streams. This review describes both technological processes and current research with the goal of catalyzing understanding towards the mining of valuable materials from complex wastes.
\end{abstract}

\section{Introduction to the circular economy}

The current industrial model can be described as a linear sequence of take-make-waste activities. The model assumes that the resources and regenerative capabilities of the earth are infinite (Fig. 1). ${ }^{1}$ While the "throw-away" model has been financially beneficial to many companies, which have benefited by producing and selling increasingly short-lived products, it has damaged the environment by requiring that valuable resources be continuously extracted. This causes an increase in waste generation and landfilling. Additionally, the benefits of the linear model are waning as pollution and required landfilling areas increase, resources become depleted, and many crucial materials become

Department of Chemistry, University of Colorado Boulder, Boulder, CO, 80300, USA. E-mail: oana.luca@colorado.edu; Tel: +1-303-735-6721

$\dagger$ Equal contributors.

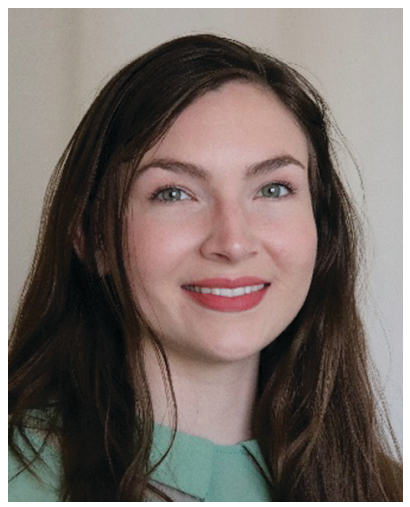

Haley Petersen graduated with a $B S$ in chemistry from the University of Arizona in 2018. In 2019 she joined the group of Prof. Oana R. Luca at the University of Colorado Boulder, where her research currently focuses on strategies for the capture and electrochemical recycling of $\mathrm{CO}_{2}$.

Haley A. Petersen increasingly scarce. Despite the hazards of a linear economy, it is still overwhelmingly the model in practice and estimates indicate that at least a third of items purchased by consumers are discarded as waste within only 6 months. ${ }^{2}$

A proposed alternative to the linear economy is the circular economy, which aims for a total restructuring of design, consumption, and waste. The three main principles of the circular economy are designing out waste and pollution, keeping products and materials in use for as long as possible, and regenerating natural systems. ${ }^{3}$ Essentially, in a circular economy, products are designed both to last longer and to use less material in the first place. Part of the design process is also dedicated to creating a plan for refurbishing and recycling end-of-life products that still contain useful materials or components (Fig. 1).

A circular economy based on recycling requires the redesign of many products to be more recycle-friendly, as items like textiles and plastics decrease in quality after undergoing the recycling process. These materials can be combusted to extract

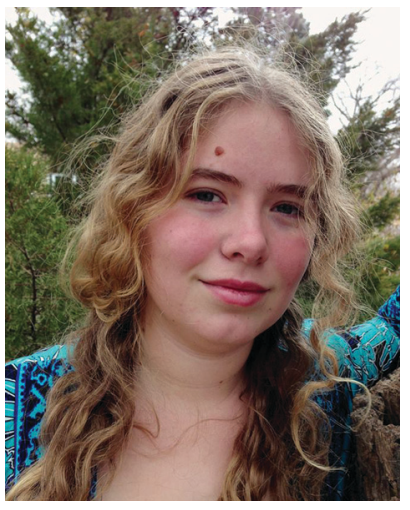

Tessa H. T. Myren
Tessa H. T. Myren joined the group of Prof. Oana R. Luca at the University of Colorado at Boulder in Fall 2017 after completing her $A B$ in Chemistry from Princeton University. Her research focuses on the conversion of waste materials such as carbon dioxide and plastics into fuel precursors, building materials, and commodity chemicals using electrochemical methods. 


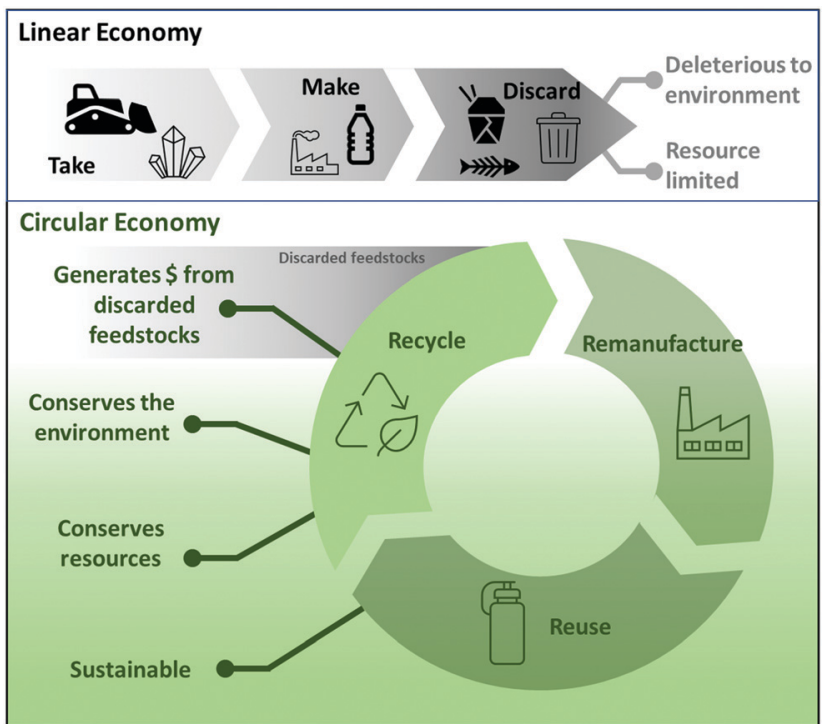

Fig. 1 Depiction of the linear vs. circular economy.

energy, but the combustion process releases pollutants and leads to losses in labor costs, materials, and energy that went into the manufacturing of the product. While recycling is an improvement over energy recovery from combustion, it is not currently an optimal solution as not everything can be recycled. Therefore, we posit that the development of new methods for the recycling of products already being manufactured on scale could enable a circular economy for the materials used. Such methods should target processes that can re- or upcycle complex, mixed end-use materials, such as those containing both organic polymers and metals.

It is estimated that the circular economy will be worth around $\$ 4.5$ trillion globally by $2030 .{ }^{1}$ Research directed to the low-cost "mining" of valuable chemicals from waste can lead to financial benefits, as well as the obvious environmental advantages associated with less waste production and less demand for resource extraction. Additionally, as materials could be retrieved from discarded products on a large scale, this approach reduces the probability of permanently running out of high-demand materials.

\section{Waste as a source of valuable materials}

To meet challenges related to resource conservation, manufacturing costs, and performance limitations across the technology landscape, innovative manufacturing methods based on electrochemistry are needed. ${ }^{4}$ However, current research efforts have little emphasis on the advancement of technologies for the recovery of molecular and metallic materials from solid wastes, rather than de novo specialty chemical synthesis or production of virgin commodity chemicals.

Methods of recovering and reusing chemical building blocks from waste materials represent a sustainable chemical route to a circular economy taking advantage of pre-existing linear manufacturing chains. The purpose of this review is to highlight electrochemical technology and current research related to such processes in the context of recovery of (1) critical raw metallic materials from solid waste and (2) valuable organic building blocks from polymer waste. These methods, deployed in tandem onto a single waste stream, can produce high dollar recycled feedstocks from discarded materials and pave the way toward enabling circularity in our currently linear economic chains. Additionally, chemical conversion technologies based on electricity benefit from the development of low-cost solar and wind energy, providing additional financial and environmental incentives. ${ }^{5}$

Although many types of waste, including polymer waste, suffer from a dearth of established electrochemical recycling methods, other areas of electrochemical recycling have proven track records of success. As discussed below, certain critical raw materials successfully undergo industrial-scale electrochemical recycling. Electrochemical methods have also proven valuable in the recycling of carbon dioxide, a waste gas with deleterious environmental effects. ${ }^{6}$ In these processes, $\mathrm{CO}_{2}$ is electrochemically converted to useful value-added materials such as hydrocarbons ${ }^{7}$ and alcohols. ${ }^{8}$ Despite challenges in interfacing capture technology with conversion chemistries, the immense progress in the realm of electrochemical $\mathrm{CO}_{2}$ recycling has enabled some of these research efforts to be implemented on a commercial scale., ${ }^{9,10}$ With such established success for recycling varied gas waste streams, electrochemical methods present a promising avenue

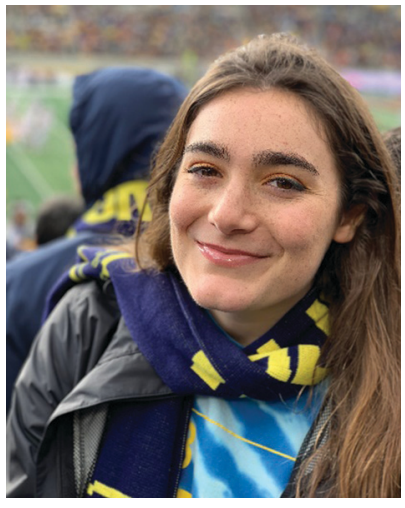

Shea O'Sullivan graduated from the University of California, Berkeley with her BS in Chemistry in 2019. She then joined Prof. Oana R. Luca's group at the University of Colorado, Boulder, where she is currently working on developing homogenous electrocatalysts for nitrogen fixation.

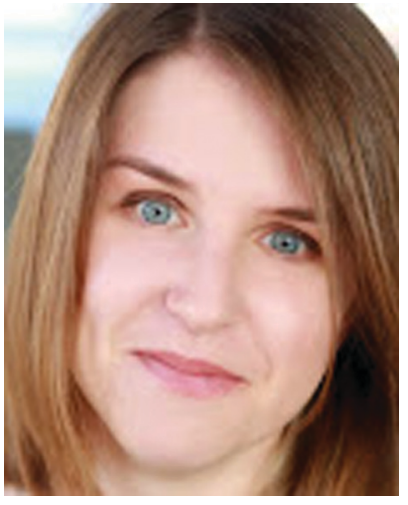

Oana R. Luca
Oana Luca is an Assistant Professor at University of Colorado Boulder, in Boulder, CO, USA. Her research team develops synthetic methods for the re-and upcycling of wastes. Her team works at the interface of organic and organometallic synthesis, electrocatalysis, mechanistic science for energy-relevant transformations and the engineering of technologies that enable economic circularity and waste valorization. 
for further progress toward a circular economy related to solid wastes. The present text seeks to highlight some mature technologies for electrochemical solid waste recycling as well as some emergent strategies in the research arena.

\section{What are critical raw materials (CRMs)?}

Many modern technologies rely on minerals and metals sourced from around the world. Although not always in the public eye, some of these minerals are critical for the manufacturing of items necessary for everyday life. ${ }^{11}$ Steel, for example, may contain nickel, copper, chromium, aluminum, tungsten, molybdenum, cobalt, and vanadium depending on the specific steel alloy. Many other products and technologies rely heavily on one or more minerals, such as gallium for backlighting in TVs and phones, graphite for rechargeable battery electrodes, and cobalt for smart phone batteries. Although some minerals are abundant and easily sourced domestically, others with less certain procurement are positioned to severely impact the United States industry, economy, and military if they become scarcer or even unobtainable.

Due to this fact, organizations in the U.S. maintain lists of critical minerals, which are minerals that are important for technologies and for which supply chains may be at risk due to factors such as high import reliance. The United States Geological Survey (USGS) currently lists 33 mineral commodities as being critical to the economy and nation while the National Defense Stockpile (NDS) maintains a collection of 38 minerals deemed critical to defense efforts. With information collected from various sources including the USGS, the Department of the Interior periodically releases an updated list of critical minerals. The list from 2018 includes 35 minerals. ${ }^{12}$

The history of the critical minerals list begins with establishment of the NDS, which began in 1939 through the execution of the Strategic Materials Act. The act authorized funding for purchasing strategic and critical materials for wartime production. The first acquisitions in 1940 included chromite, manganese, and tin. The list has evolved over time in response to changing technologies. In 1993, 44 materials in excess or considered obsolete were sold off to the private sector including aluminum, cobalt, nickel, and silver. Today the U.S. stockpile contains thirty-seven materials with a value of $\$ 1.152$ billion. ${ }^{13}$ A 2014 congressional act determined the need to acquire rare earth elements (REEs) and to determine better ways of recycling REEs from scrap and waste. In 2017, an executive order officially defined a "critical mineral" as being a non-fuel which is essential to economic and national security, which has an at-risk supply chain, and which would cause harm to the nation if supply was disrupted. ${ }^{13}$ The Department of the Interior and USGS then, as part of the executive order, published the current list of 35 minerals. $^{12}$

One of the driving forces behind changes in the list is the development of new technologies, including green technologies, and the change in demand for minerals based on those developments. This can mean either increased demand, leading to new critical designation for materials that previously were not critical, or decreased demand, causing a mineral to lose its critical status. Recent changes in demand that may affect the future of the list include: decreased demand for aluminum, chromium, manganese, platinum, rare earth elements, titanium, and tantalum; slowly increasing demand for lithium, germanium, and graphite; and rapidly growing demand for tellurium, niobium, and indium. ${ }^{11}$ Additionally, the U.S. has a high import reliance for materials like yttrium, gallium, magnesium metal, tungsten, bismuth, and rare earth elements, which could be a security risk and cause concerns with the supply chain in the future. ${ }^{11}$

An increase in mining and other extraction techniques worldwide would increase the availability of certain critical minerals, but these operations would require time and capital and are tied to concerns about ethical labor and environmental impact. Additionally, several critical minerals are not mined in pure form but as a mixture with other minerals, thus raising the level of complexity of their collection and use. Finally, although not a requirement for critical mineral status, several of these minerals are geologically scarce, and global resources may be depleted especially with increased consumption. Thus, recovery and recycling of the minerals from secondary sources is a priority to supply minerals and reduce the pollution caused by disposal.

Several types of non-electrochemical CRM recycling methods are used. Pyrometallurgy and hydrometallurgy are the two most common. Pyrometallurgy primarily uses heat to extract metals, requiring high energy costs, while hydrometallurgy produces aqueous solutions from which the metals are extracted, but produces hazardous chemical waste. These processes are usually followed by a refining process which can also be pyrometallurgical or hydrometallurgical in nature with the addition of electrochemical methods. Although less common, electrochemical extraction methods have also been studied. Electrochemistry offers a green alternative to many techniques, as it uses electrons, a potentially "green reactant," and can avoid pollution and waste. This discussion focuses on technical aspects related to the use of electrochemical methods for the recycling of certain critical metallic minerals, using the Department of the Interior's 2018 final list as the primary indicator of criticality. ${ }^{12}$ The discussion on minerals is ordered by price as shown in Table 1, with manganese as the cheapest of the minerals by weight and gallium as the most expensive. Pricing is not, however, indicative of the magnitude of consumption and discarding, as the scales of use and recycling are independent from price. A brief discussion of common terminology and techniques is provided below.

\subsection{Glossary of terms}

Throughout the following sections of this manuscript some possibly unfamiliar terms will be used, which are defined here for convenience. The term "apparent consumption" is defined by the USGS as in eqn (1).

$$
\text { Apparent Consumption }=\text { Production }+ \text { Imports }- \text { Exports }
$$$$
\pm \text { (Stock Change) }
$$ 
Table 1 Critical minerals in this manuscript organized by increasing price

\begin{tabular}{llc}
\hline Critical mineral & Mineral form and/or price type ${ }^{a}$ & Price $^{a}(\$$ per lb) \\
\hline Manganese & $46-48 \%$ Mn metallurgical ore, cost, insurance, and freight U.S. ports & 0.003252 \\
Aluminum & Ingot, average U.S. market (spot) & 1.147 \\
Antimony & Metal average & 3.88 \\
Titanium & Titanium sponge metal & 4.173 \\
Chromium & Metal & 5.146 \\
Lithium & Battery grade lithium carbonate & 7.711 \\
Cobalt & U.S. spot, cathode & 37.43 \\
Indium & New York dealer & 170.1 \\
Gallium & High-purity, refined & 230.4 \\
${ }^{a}$ Prices for mineral forms and price types were obtained from the USGS Mineral Commodities Summaries 2020 and converted to $\$$ per lb. ${ }^{14}$
\end{tabular}

Old scrap refers to scrap from items that have been used by a consumer. In contrast, new scrap is material leftover from the manufacturing process. New scrap tends to be easier to recycle, particularly for metals, while old scrap is usually a more complicated mixture and has more contaminants.

Superalloys are alloys with increased strength, temperature resistance, and anti-corrosion properties specifically for use in extreme applications such as jet engines. Superalloys are rarely recycled outside of limited new scrap recycling conducted by manufacturers. Additionally, recycling of superalloys through pyrometallurgy, hydrometallurgy, or a combination often results in a loss of material up to $20 \%{ }^{15}$

\subsection{Overview of electrochemical recycling techniques for CRM recovery}

Some of the minerals in the CRM lists have few to no methods of recycling in active, large-scale use such as the antimony used in flame retardants ${ }^{16}$ or gallium in LEDs and solar cells. ${ }^{14}$ For others, established recycling practices are usually included in the two categories of pyrometallurgy and hydrometallurgy which require high temperatures or hazardous solvents. Electrochemistry is a green alternative to many of these techniques and can recover materials from complex critical mineral mixtures for which traditional methods, such as hydrometallurgy and pyrometallurgy, are less effective or non-existent. For example, techniques such as slurry electrolysis ${ }^{17,18}$ and electrodeposition ${ }^{19,20}$ have been used to collect minerals like manganese, aluminum, and antimony from complex mixtures. Because many metal ions have different deposition voltages, electrochemical techniques can successfully separate mixed wastes containing a variety of metal ions, presenting an advantage over techniques that are sensitive to other metal ion content. Additionally, combining electrochemical methods with some selective chemical deposition can further improve selectivity toward certain metal ions. Especially when used in combination, these two methods may help with the separation and purification of products. Similarly, electrical fields can be used to collect indium from indium tin oxide on broken glass substrate. Continued developments in these types of methods are necessary. Of special interest are methods that can retrieve valuable products out of end-product wastes that combine both metallic and organic components. Electrochemistry is therefore uniquely poised to address some of the complexity challenges associated with mixed wastes, but the field of electrochemical methods for the recovery of organic materials remains in its infancy. This section highlights mature technological recycling methodologies in the field of CRMs that may cross-pollinate interest in the field of mining organic materials from complex mixtures. A summary of electrochemical recycling techniques for the CRMs discussed in this section is offered in Table 2.

\subsection{Common techniques}

Some common electrochemical techniques applicable to CRM recycling are briefly defined below for brevity in later discussions.

- Electrostatic separation applies constant currents to two electrodes. The difference in electrical conductivity of materials (metal and non-metal) leads to separation of materials. ${ }^{21}$

- Electrodeposition is the use of electric current to deposit solid metal on the cathode of an electrochemical system.

- Electrocoagulation is used to produce metal ions in solution simultaneously with the generation of hydroxyl groups and hydrogen gas. Electrons affect the charges of suspended solid and oils. These species all coagulate to form flocs which can then be removed from solution and processed.

- Electrodialysis (ED) uses ion-exchange membranes and electrical driving forces to transport aqueous ions, such as transporting cations into catholyte and restricting the flow of anions.

- Electrochemical ion exchange is a combination of electrodialysis and ion exchange. ${ }^{22}$

- Electro-electrodialysis (EED) combines electrolysis and $\mathrm{ED}$, allowing the separation of ions from solutions and then regeneration of oxidation or ionic forms through electrolysis. ${ }^{23}$

- Electrodeionization is set up similarly to electrodialysis but uses ion-exchange resins in the dilute compartment. ${ }^{23}$

- Electroflotation uses uniform and tiny bubbles of hydrogen and oxygen generated by water splitting to cause the flotation of all solid particles in a solution, thus enabling the easy removal of solids. Electroflotation produces smaller bubbles compared to other flotation techniques, can be placed to cover the entirety of tanks, is safe to use, and produces easily monitored visible results. ${ }^{24}$

- Slurry electrolysis is a method which can convert solid metal-containing particles first by anodic electrodissolution followed by electrodeposition. ${ }^{17}$

\subsubsection{Manganese}

Sources and uses. Although not a geologically scarce mineral, ${ }^{42}$ $90 \%$ of its production ${ }^{14}$ is for in metallurgical applications. 
Table 2 Electrochemical methods for the recycling of critical raw materials: strengths and weaknesses

\begin{tabular}{|c|c|c|c|}
\hline Material & Experimental conditions & Methods and strengths & Weaknesses of methods \\
\hline Manganese $^{25,26}$ & $\begin{array}{l}\mathrm{MnO}_{2} \text { can be produced by } \\
\text { cyclic voltammetry in } 1 \mathrm{M} \\
\mathrm{Na}_{2} \mathrm{SO}_{4}{ }^{25} \text { from the cathodes of } \\
\text { fnent } \mathrm{Zn}-\mathrm{C} \text {. }\end{array}$ & $\begin{array}{l}\text { Electrodeposition: offers } \\
\text { enhanced control over } \\
\text { morphology }\end{array}$ & $\begin{array}{l}\text { Chemical recovery methods } \\
\text { primarily result in manganese } \\
\text { oxides }\end{array}$ \\
\hline
\end{tabular}
spent $\mathrm{Zn}-\mathrm{C}$ batteries

Electrodeposition: electrolytic manganese can be obtained by treating manganese ore or scrap at high temperature to obtain MnO that can then be subjected to cathodic conditions to deposit Mn metal. The Mn

flakes produced are then annealed at $500{ }^{\circ} \mathrm{C}^{27}$

Slurry electrolysis: allows for a Electrodeposition: unwanted one-pot extraction without the side products observed when need for prior leaching steps, undivided electrolysis cells are usually at room temperature and used (undesired oxidation in closely related to production of the case of $\mathrm{Mn}^{2+}$ to $\mathrm{Mn}^{3+}$ being

Aluminum $^{29,30}$ Electrodeposition: 98\% pure aluminum, $103{ }^{\circ} \mathrm{C}, 1.0-1.8 \mathrm{~V}$, chloroaluminate ionic liquid, $3.2-6.7 \mathrm{~kW} \mathrm{~h} \mathrm{~kg}^{-130}$

Electrodeposition: energy consumption of $\sim 2 \mathrm{~kW} \mathrm{~h} \mathrm{kg-Al}{ }^{-129}$

Antimony ${ }^{16,31}$ Electrodeposition: 4 hours to recover antimony from $200 \mathrm{~mL}$ of solution at $3500 \mathrm{mg} \mathrm{L}^{-1}$ concentration $^{31}$ at $3 \mathrm{~V}$ applied potential $409 \mathrm{~kW} \mathrm{~h} \mathrm{~kg}^{-1}$ energy cost at high concentrations ${ }^{31}$

Titanium $^{32,33} \quad 3 \mathrm{~V}$ applied to $\mathrm{HCl}$ solution. Metal ions are produced and $\mathrm{Al}$ and $\mathrm{Ti}$ can be recovered simultaneously from aircraft parts. $138 \mathrm{~kg}$ of Ti per ton of aircraft scrap after electrodeposition and resmelting ${ }^{34}$

Chromium $^{22,24}$ Electroflotation for collection of chromium from wastewater:
$1 \mathrm{~kW} \mathrm{~h} \mathrm{~m}^{-324}$

EIX: $98.82 \%$ removal, $12.5 \mathrm{~V}$, $72.39 \mathrm{~kW} \mathrm{~h} \mathrm{~kg}^{-122}$ electrolytic manganese

Electrolysis/electrodeposition: can separate aluminum from more complex mixtures and alloys than traditional recycling does; also faster than the shredding, grinding, melting process; room temperature in some cases

Electrodeposition: antimony separation from lead-acid accumulator solution does not require any additives or electrolyte $^{16}$ an example) Electrodeposition: the production of electrolytic Mn requires removal of contaminants by steps such as precipitation with $\mathrm{H}_{2} \mathrm{~S}$ and processing at high temperatures

Electrodeposition: traditional recycling for aluminum already uses very little energy with high quality and purity product. It does require $\mathrm{HCl}$ or chloroaluminate ionic liquids for the case of aluminum. Some conditions require $103{ }^{\circ} \mathrm{C}$, which is still lower than smelting temperatures but higher than ideal Electrodeposition in hydrometallurgical recycling: requires leaching with $\mathrm{H}_{2} \mathrm{SO}_{4}$, corrosive

Electrodeposition: separation/ recycling of complex mixtures and alloys possible

Electrochemical honing: allows automobile/aircraft parts to be reused repeatedly while still maintaining high quality. Room temperature, no additives necessary $^{32,33}$

Can help counter unwanted oxidation from other methods

Production of 10 tons of titanium metal involves a process that requires 10 days at $950{ }^{\circ} \mathrm{C}$, therefore its recycling is considerably financially and resource advantageous $^{35}$

Electrodialysis: achieves $70 \%$ reduction in water consumption loss on pilot plant scale ${ }^{23}$ electrochemical deoxygenation
Electrochemical methods for separation still must be followed by resmelting

Current electrochemical methods applied on scale are not efficient in high-O-content Ti scrap. Kang reported an process that is able to circumvent this obstacle, but the process has yet to be adopted on scale ${ }^{36}$ Chemical recycling methods downcycle the Ti scrap to ferrotitanium

Electrodeposition: not as efficient and electrocoagulatio or electroflotation and also more costly

Electrodeposition: typically used to collect pure chromium but more often to remove it from wastewater and reuse it
Notes on applications on scale

American Manganese Inc.

(hydrometallurgical followed by electrowinning/electrodeposition) - in September 2020 processed $292 \mathrm{~kg}$ of Li-ion battery cathode material per day (pilot plant) ${ }^{26}$ - aiming for 3 tons per day; ${ }^{28}$ manganese recovered in this process

Remelting of pure $\mathrm{Al}$ scrap is an efficient process that is more cost effective than the electrolytic production, $\sim 5 \%$ of the cost

Used as part of a hydrometallurgical process (electrodeposition) on industrial scale

Used in production electrorefining

Poeton industries uses electrodialysis stock in factory $^{23}$ 
Table 2 (continued)

\begin{tabular}{|c|c|c|c|c|}
\hline Material & Experimental conditions & Methods and strengths & Weaknesses of methods & Notes on applications on scale \\
\hline Lithium $^{18,37}$ & $\begin{array}{l}\text { Electrodialysis: } 88 \% \text { yield } \\
\text { produces lithium carbonate } \\
\text { that meets national standard } \\
\\
\text { Electrodialysis method: } \\
\text { lithium salts > } 95 \% \text { purity, } \\
80 \% \text { extraction efficiency }{ }^{18} \\
\text { Slurry electrolysis: } 99 \% \\
\text { efficient for electro-leaching, } \\
62-77 \% \text { current efficiency for } \\
\text { electrodeposition } \text { step }^{18}\end{array}$ & $\begin{array}{l}\text { With a few exceptions, lithium } \\
\text { is rarely recycled so any } \\
\text { techniques electrochemical or } \\
\text { chemical are at the forefront of } \\
\text { need }\end{array}$ & High cost of electrodialysis & $\begin{array}{l}\text { American Manganese Inc. } \\
\text { (hydrometallurgical followed } \\
\text { by electrowinning/electro- } \\
\text { deposition): } 292 \text { kg of Li-ion } \\
\text { battery cathode material per } \\
\text { day (pilot plant) }{ }^{26} \text { - aiming for } \\
3 \text { tonne per day; }{ }^{28} \text { lithium is } \\
\text { recovered in this process }\end{array}$ \\
\hline Cobalt $^{38,39}$ & $\begin{array}{l}\text { Electrodeposition: of } \\
\text { lithium-ion battery scrap. } \\
\text { Up to } 96.90 \% \text { charge } \\
\text { efficiency. } 1 \mathrm{~V} v s . \mathrm{Ag} / \mathrm{AgCl}^{38} \\
\text { Electrodeposition: }-0.9,-1.1 \text {, } \\
\text { and }-1.2 \mathrm{~V} v \text { s. } \mathrm{Ag} / \mathrm{AgCl} \text { all } \\
\text { used }^{39}\end{array}$ & $\begin{array}{l}\text { Electrodeposition: cobalt } \\
\text { can be recovered from old } \\
\text { batteries, even though } \\
\text { lithium-ion batteries have now } \\
\text { been phased into main uses }\end{array}$ & $\begin{array}{l}\text { Electrodeposition from super- } \\
\text { alloys does require } 70{ }^{\circ} \mathrm{C} \text {; } \\
\text { electrodeposited cobalt would } \\
\text { still need to be treated at } \\
300{ }^{\circ} \mathrm{C} \text { to get } \mathrm{Co}_{3} \mathrm{O}_{4} \text { to be } \\
\text { used in lithium-ion battery } \\
\text { cathodes again }{ }^{39}\end{array}$ & $\begin{array}{l}\text { American Manganese Inc. } \\
\text { (hydrometallurgical followed } \\
\text { by electrowinning/electro- } \\
\text { deposition): } 292 \mathrm{~kg} \text { of Li-ion } \\
\text { battery cathode material per } \\
\text { day (pilot plant) }{ }^{26} \text { - aiming for } \\
3 \text { tonne per day; }{ }^{28} \text { cobalt is } \\
\text { recovered in this process }\end{array}$ \\
\hline Indium $^{40,41}$ & $\begin{array}{l}\text { Electrodeposition: } 98.1 \pm 2.5 \% \\
\text { recovery of indium from } \\
\text { CIGS }^{41} \text { after selenium recovery }\end{array}$ & $\begin{array}{l}\text { Electrostatic: room temperature, } \\
\text { can be removed from broken } \\
\text { substrate or can leave substrate } \\
\text { intact, no use of additives, } \\
\text { solvents, otherwise }^{40}\end{array}$ & $\begin{array}{l}\text { Electrochemical methods that } \\
\text { rely on delamination of ITO } \\
\text { from substrate layers are } \\
\text { incompatible with broken } \\
\text { samples }\end{array}$ & $\begin{array}{l}\text { Potential for electrochemical } \\
\text { methods for Indium recycling } \\
\text { exists; no known pilot scale } \\
\text { systems exist }\end{array}$ \\
\hline Gallium $^{41}$ & $\begin{array}{l}\text { Electrodeposition potentials } \\
\text { for gallium do not lead to the } \\
\text { deposition of metallic forms, } \\
\text { although separation from } \\
\text { other metals is achieved }\end{array}$ & $\begin{array}{l}\text { Electrodeposition: can } \\
\text { separate gallium from } \mathrm{CIGS}^{41}\end{array}$ & $\begin{array}{l}\text { Gallium is left in solution and } \\
\text { will need other methods to } \\
\text { deposit it }\end{array}$ & $\begin{array}{l}\text { No methods known to recycle } \\
\text { Ga out of old scrap, but some } \\
\text { recent reports indicate that } \\
\text { new scrap has been recycled, } \\
\text { but not electrochemically }{ }^{14}\end{array}$ \\
\hline
\end{tabular}

There is no substitute for $\mathrm{Mn}$ in these applications. ${ }^{27}$ As a consequence its supply chain is susceptible to disruptions. Manganese is therefore considered critical by several countries, particularly because of its use in steels, superalloys, dry cell batteries, and clean energy technologies. ${ }^{11,12,14,43}$ Recessions in 2001 and 2008 caused delays in mining and processing capacity expansions, which affected manganese supply. ${ }^{11}$ This was especially impactful on the U.S. because of a $100 \%$ import reliance with the main supply coming from South Africa, Gabon, Australia, and Georgia. South Africa has about $74 \%$ of the world's identified manganese resources. Although manganese is not recycled on its own, it is incidentally recycled along with metal scrap and can be recovered from steel slag. ${ }^{14}$

Manganese is stockpiled in three forms: metallurgical grade manganese ore, high carbon ferromanganese, and electrolytic manganese metal. ${ }^{14}$ Electrolytic manganese metal is $99.9 \%$ pure manganese metal made by roasting manganese ore to obtain $\mathrm{MnO}$ calcine, dissolving in sulfuric acid, precipitating contaminants using hydrogen sulfide, and finally depositing manganese metal using an electrolytic cell. The flakes removed from the cathode of the electrolytic cell are then heated to $500{ }^{\circ} \mathrm{C}$, which produces electrolytic manganese powder. ${ }^{27}$ Electrolytic manganese was added to the NDS in 2019. ${ }^{14}$ Although recycling manganese outside of metal alloy scrap is not common, it has been recovered from batteries using thermal treatments and chemical methods on a laboratory scale. ${ }^{44-46}$

Electrochemical recycling methods. Manganese is used in zinc-carbon batteries, which are dry cell batteries commonly used in households as non-rechargeable batteries. Ali et al. used cyclic voltammetry scanning in $1 \mathrm{M} \mathrm{Na}_{2} \mathrm{SO}_{4}$ to prepare $\mathrm{MnO}_{2}$ nanoflowers from the cathode powder (containing $\mathrm{Mn}_{3} \mathrm{O}_{4}$ ) of such spent batteries. This manganese oxide can find reuse in supercapacitors. ${ }^{25}$ Manganese from spent $\mathrm{Zn}-\mathrm{MnO}_{2}$, mainly $\mathrm{Mn}_{3} \mathrm{O}_{4}$ and $\alpha-\mathrm{MnO}_{2}$, can also be recovered by precipitation followed by electrodeposition and anodization. The charge efficiency achieved $85 \%$ for the electrodeposition process but the anodic process is much less efficient due to the undesired oxidation of $\mathrm{Mn}^{2+}$ to $\mathrm{Mn}^{3+} \cdot{ }^{47}$

Recovery from nickel metal hydride batteries produced $\mathrm{Mn}_{3} \mathrm{O}_{4}$ via electrodeposition at $-1.1 \mathrm{~V} v$ s. $\mathrm{Ag} / \mathrm{Ag} \mathrm{Cl}$ and a charge density of $-90 \mathrm{C} \mathrm{cm}^{-2}$ (Scheme 1). ${ }^{48}$ Manganese is a component in lithium-ion battery cathodes as well and can be collected using slurry electrolysis. An example of such a process recovered $\mathrm{MnO}_{2}$ with an electro-leaching efficiency of $92 \%$ and a $62-77 \%$ current efficiency. ${ }^{18}$

Outlook. The possibility of a disrupted supply chain combined with the lack of recycling methods render developments in manganese recycling essential for the future. Electrochemistry is already used industrially for the production of pure electrolytic manganese, suggesting that it is a viable option for the recovery and refining of manganese. This is also demonstrated by the use of electrochemistry, primarily electrodeposition-based techniques, to recover manganese from battery cathodes often in tandem with the collection of other materials, increasing the cost-effectiveness.

Currently, American Manganese Inc. is scaling up a recycling process for Li-ion battery cathodes which include manganese. Although the extraction and separation are primarily hydrometallurgical, electrodeposition is used for the final separation 


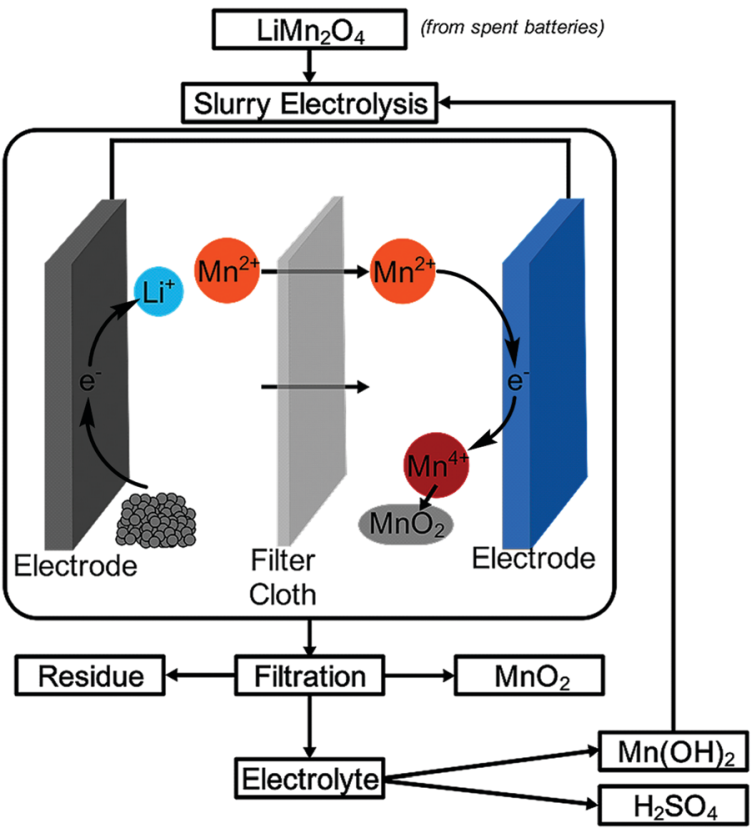

Li et al. 2017

Scheme 1 Device operation for the recovery of manganese from spent batteries using slurry electrolysis.

and purification of manganese metal. The company plans to achieve a 3 ton per day recycling plant with scaling as of October 2020 reaching $292 \mathrm{~kg}$ per day of cathode material. ${ }^{26,28}$

\subsubsection{Aluminum}

Sources and uses. Although aluminum is not stockpiled by the NDS $^{14}$ and is not geologically scarce ${ }^{14,42}$ it is considered a critical mineral in the U.S. ${ }^{11,12,14}$ Aluminum is common, inexpensive, and often smelted domestically. However, it is used in a large variety of technologies, and the U.S. has a $100 \%$ import reliance for bauxite, which is used in aluminum production, making aluminum a critical mineral. ${ }^{11,14,43}$ Some of the notable examples of aluminum usage are in aircraft, naval vessels, vehicles, packaging, and power transmission lines. The average price for aluminum on the U.S. market in 2018 was 114.7 cents per $\mathrm{lb}$.

Traditional recycling methods. Aluminum is most recycled simply by shredding aluminum scrap, melting, and reforming. This process requires only $5 \%$ of the energy necessary to initially produce the aluminum and recycling repeatedly has little effect on quality and purity. ${ }^{49}$ This makes aluminum the most commonly recycled metal in the world with a $65 \%$ recycling rate in the U.S. in $2011 .{ }^{49}$ Although this method of recycling is very effective particularly for scrap that is mostly composed of aluminum, it is less effective for mixtures of scrap, particularly those that contain potentially toxic compounds. Aluminum metal matrix composites, where aluminum is used as the matrix phase and another constituent (often $\mathrm{SiC}$ or $\mathrm{Al}_{2} \mathrm{O}_{3}$ ) is the reinforcement, are traditionally recycled through melting and casting into ingots. Salt fluxing, a technique using molten salts, is used with certain composites to aid removal of impurities, such as ceramic particles, while also protecting the aluminum from oxide generation..$^{49}$ Both methods require high temperatures.

Electrochemical recycling methods. Electrochemical recycling techniques have been shown as effective in recycling aluminum from mixtures. One example of such a situation is in aircraft. Planes can contain between $60-80 \%$ aluminum alloys, but they also contain other metals including chromium, cobalt, and titanium with many in separate layers. If shredded or recycled using mechanical methods, these metal layers are mixed, thus making the process more complex. However, Benyahia and Hausler demonstrated that electrolysis in $\mathrm{HCl}$ at $3 \mathrm{~V}$ could dissolve the middle layer of aluminum in 24 hours, simultaneously isolating the aluminum and titanium layers. Per ton of metal, $466 \mathrm{~kg}$ of aluminum could be recovered and the process was typically faster than the alternative method involving grinding and melting. ${ }^{34}$

Electrodeposition has also been studied particularly for the recycling of aluminum-containing alloys, with many methods focusing on the use of chloroaluminate ionic liquids. ${ }^{19,20,50,51}$ One particular study by Kamavaram et al. investigated the use of electrodeposition to retrieve $>98 \%$ pure aluminum at a reduced temperature of approximately $103{ }^{\circ} \mathrm{C}$. A pure copper cathode, aluminum reference electrode, and aluminum matrix composite anode were used, and a constant potential (1.0-1.8 V) was applied across the electrodes. The electrolyte used was a chloroaluminate ionic liquid, and the entire experiment was performed under a flow of inert argon with constant stirring. Aluminum was deposited on the cathode and could be mechanically collected. Overall, the process used between $3.2-6.7 \mathrm{~kW} \mathrm{~h} \mathrm{kg-Al}{ }^{-1}$ and had no emission of pollutants. ${ }^{30}$ Later, a similar setup also using chloroaluminate ionic liquids was used to recycle aluminum alloys and additionally was found able to collect pure copper from alloys containing copper. This process was performed at room temperature with an energy consumption of $\sim 2 \mathrm{~kW} \mathrm{~h} \mathrm{kg-Al}{ }^{-1} .^{29}$ Slurry electrolysis can also be used to collect aluminum from printed circuit board waste. ${ }^{52}$

Outlook. Although aluminum is abundant in the Earth's crust and the recycling methods traditionally used are extremely effective on mostly pure aluminum, electrochemistry has been shown to effectively recover $\mathrm{Al}$ from complex mixtures. In materials such as alloys and superalloys, the electrochemical recovery of aluminum can additionally help with the separation of rarer or more hazardous components, thus reducing waste and pollution that comes from the aluminum industry. Electrochemical methods may also be more useful in smaller, on-site recycling operations than methods that require extreme temperatures.

\subsubsection{Antimony}

Sources and uses. Antimony was added to the NDS in December 2018 and in 2018 was sold in the U.S. for an average $\$ 3.88$ per $\mathrm{lb}^{14}{ }^{14}$ The primary use of antimony is in antimony trioxide, $\mathrm{Sb}_{2} \mathrm{O}_{3}$, a common flame retardant. ${ }^{16}$ It is also used as a catalyst in PET plastic production as well as in the preparation of antimonial lead which is common in items such as certain engines, ammunition, solder, tank linings, lead-acid accumulators (car batteries), and anti-friction bearings. ${ }^{16}$ Antimony is also 
finding growing use in diodes. The United States imports $84 \%$ of its antimony, primarily from China, Thailand, Belgium, and India. ${ }^{14}$ Despite the large demand for antimony, it is considered geologically very scarce and extractable global resources are expected to be depleted well before 2050 if current extraction rates are maintained. ${ }^{42}$ No marketable antimony was mined in the U.S. in 2019 and China accounts for over $60 \%$ of global mine production. ${ }^{14}$ Overall, antimony is considered of high economic importance and of high supply risk. ${ }^{11}$ Additionally, the EPA considers antimony compounds to be pollutants, and acute exposure causes irritation of eyes, skin, and lungs, while chronic exposure will worsen lung and heart conditions. ${ }^{53}$

Traditional recycling methods. Currently, there is no known method to recycle antimony from flame retardants. ${ }^{35}$ Considering the technological and economic importance of antimony along with the upcoming depletion of geological sources, recycling methods for antimony are critical. Already, antimony recycling supplies account for $\sim 14 \%$ of domestic consumption, which is mostly recovered from lead-acid batteries or antimonial lead. ${ }^{14}$ The recycling of lead-acid battery scrap or other antimonial lead scrap through smelting/reduction followed by refining can produce pure lead, lead-antimony alloys, and a low-quality $\mathrm{Pb} / \mathrm{Sb}$ mixed oxide which cannot be used in flame retardants. ${ }^{35,54}$ Since one of the primary uses of antimony is lead-acid accumulators, most recycling technology and large-scale recycling focuses on the collection of antimony from such systems. ${ }^{55,56}$ Primarily, the recovery of antimony from flame retardants and other non-metal uses is currently not economically feasible but may be technically feasible such as through the collection of ashes from incinerating these products. ${ }^{42}$ Antimony can also be recovered from spent catalysts, with a chief example being catalysts for the production of poly(ethylene terephthalate) (PET). Several studies have thus focused on the recycling of antimony from spent catalysts, including chlorination followed by distillation of $\mathrm{SbCl}_{5},{ }^{57}$ or by reduction to $\mathrm{SbCl}_{3}$ followed by extraction. ${ }^{58}$

Electrochemical recycling methods. Electrochemistry in the form of electrodeposition is used during industrial hydrometallurgical recycling after leaching of sulfuric acid. ${ }^{16}$

A method for the collection of antimony from lead-acid accumulators based on electrochemical deposition was studied by Bergmann and Koparal and is shown in Scheme $2 .{ }^{31}$ It was found that a divided cell was necessary to prevent the oxidation of $\mathrm{Sb}$ (III) to $\mathrm{Sb}(\mathrm{v})$. The cell type shown in Scheme 2 with experiment parameters of $3500 \mathrm{mg} \mathrm{L}^{-1}$ initial $\mathrm{Sb}, 50 \mathrm{~A} \mathrm{~m}^{-2}$ current density, $200 \mathrm{~mL}$ volume, and an applied potential of $3 \mathrm{~V}$ resulted in almost complete removal of antimony after 4 hours at an energy cost of $409 \mathrm{~kW} \mathrm{~h} \mathrm{~kg}{ }^{-1}$. Experiments at lower concentrations showed higher energy costs. ${ }^{31}$

Another method was used to extract metals, including antimony, from nonferrous metals industry waste, starting with dissolution via sulfuric acid and followed by electrolysis. $\mathrm{Sb}_{2} \mathrm{~S}_{3}$ was precipitated from the catholyte solution using $\mathrm{H}_{2} \mathrm{~S} .{ }^{59}$

Although no electrochemical methods have been explored for the recycling of antimony containing flame retardants, it

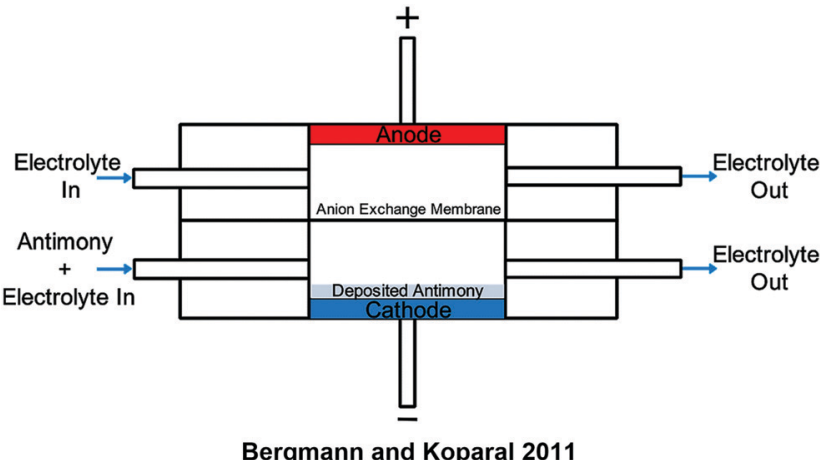

Scheme 2 A cross-section schematic of a flow-through cell used with an anion exchange membrane for the deposition of antimony from lead-acid accumulators. Antimony flows through the cathodic chamber and is deposited on either a standard 2D or a 3D electrode. Recovery then simply requires removal from the electrode surface. (Adapted with permission from M. E. H. Bergmann, A. S. Koparal, Electrochemical antimony removal from accumulator acid: Results from removal trials in laboratory cells, 2011, 196, 59-65. Copyright 2011 Elsevier. ${ }^{31}$ )

may be possible to use electrochemistry as part of a process beginning with the concentration of the flame retardant, likely into ashes through incineration, ${ }^{42}$ which then could be further extracted and redeposited as antimony through electrochemical means.

Outlook. Overall, antimony is one of the most important critical minerals to consider recycling and recovering due to its scarcity. Electrochemistry has been shown as advantageous to the recovery of antimony from spent catalysts and lead-acid batteries, but no advances have been made with regards to flame retardants, the primary use of antimony. As this use currently has no known recycling method, it is important to explore electrochemical methods for this product.

\subsubsection{Titanium}

Source and uses. Titanium is usually supplied in one of two forms: titanium mineral concentrates and titanium sponge metal. Titanium mineral concentrates are ores which have been refined to remove the bulk of waste materials. Titanium sponge metal is the purest form of titanium, resulting from the use of the Kroll process on titanium ore. A majority of titanium (80\%) is used in aerospace with the remainder going to a variety of sectors including medical implants, power generation, armor, and consumer applications. ${ }^{14}$ Of the two forms, titanium sponge is the main contributor to these areas, whereas titanium mineral concentrates are chiefly used to make $\mathrm{TiO}_{2}$ pigments. Titanium is critical primarily due to its role in aerospace superalloys and alloys along with military armor plate, ${ }^{12,43}$ but is not one of the minerals in the NDS. ${ }^{14}$

The U.S. imports $86 \%$ of titanium sponge metal from Japan, Kazakhstan, Ukraine, China, and Russia. 93\% of titanium mineral concentrates are imported from South Africa, Australia, Canada, and Mozambique. In the U.S. there is some domestic production of titanium sponge metal in Nevada and Utah. Titanium dioxide, another important product from titanium, was produced in five facilities in the U.S. and is primarily used in paints and plastics. ${ }^{14}$ 
Traditional recycling methods. Unlike many of the minerals discussed here, recycling of titanium supplies a substantial part of domestic consumption. ${ }^{43}$ Titanium scrap (primarily new scrap) is recycled by the titanium, steel, and superalloy industries. ${ }^{14}$ Aerospace use of titanium generates a high amount of scrap: $80 \%$ of the input material becomes scrap. High quality scrap can be recirculated as titanium while contaminated scrap is usually diverted to ferrotitanium or additives to other metals. ${ }^{35}$ Recycling of titanium saves a considerable amount of energy since 10 tons of titanium takes 10 days at $950{ }^{\circ} \mathrm{C}$ for its production. In fact, the production of titanium requires 50\% more energy than that of aluminum. ${ }^{34}$ Scrap, which is being recycled back into titanium, is usually remelted by cold hearth melting or vacuum arc remelting. Either method introduces oxygen contamination. ${ }^{35}$

Remanufacturing of parts for aerospace or automotive applications is extremely cost effective but often requires a multistep process. Post-machining is often required after an initial layer deposit or cladding technique in order to achieve appropriate surface quality. Grinding is the traditional method of postmachining and uses abrasive polishing or lapping processes to remove small material and complete a micro finish on the clad surface. This process, however, can cause small defects due to point forces which eventually cause failures in the surfaces. ${ }^{32,33}$

Electrochemical recycling methods. Titanium can be recovered from layered aircraft alloys in which titanium, aluminum, and steel layers are common. When $3 \mathrm{~V}$ was applied with a solution of $\mathrm{HCl}$, the aluminum layer dissolved, resulting in the isolation of the titanium layer as well. Per ton of aircraft metal, $138 \mathrm{~kg}$ of titanium was recovered which could be resmelted. ${ }^{34}$ Additionally, electrochemical honing can be used on titanium parts, allowing the remanufacturing of parts at lower cost and skirting the need to produce new parts. Electrochemical honing is a method of postmachining particularly for aerospace or automotive parts which is capable of generating a controlled surface finish including for hard materials such as titanium. Electrolytic action is found to be the cause of $90 \%$ of the material removal in the process. ${ }^{32,33} \mathrm{~A}$ visual description of the electrochemical honing process is provided in Scheme $3 .^{32,33}$

Kong et al. reported in 2019 a process allowing for the recycling of Ti scrap with high $\mathrm{O}$ concentration using an electrochemical deoxidation process. Although the process has not been

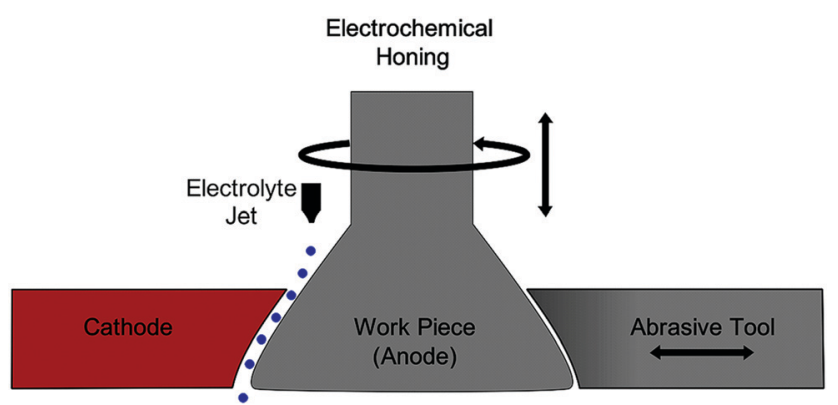

Scheme 3 A schematic of the setup for electrochemical honing as used to achieve controlled surface finish in remanufacturing processes such as for engine valves. used on an industrial scale, the authors proposed that electrochemical cells already used in the Kroll process may be applied for this new process as well, taking advantage of already established industrial frameworks. ${ }^{36}$

Outlook. Titanium is readily recyclable through traditional means, and recycling reduces energy costs dramatically. However, mixtures of titanium will typically downcycle to lower quality ferrotitanium or additives instead of being reusable as pure titanium. Although electrochemical methods are not commonly used on titanium, it can be used to help reduce the need to make new parts and can recover pure titanium from complex mixtures.

\subsubsection{Chromium}

Source and uses. Chromium is an important component in steel production, superalloys, and batteries. ${ }^{14}$ Chromium salts are also commonly used in photography, inks, paints, and textiles. $^{22}$ Despite the mild geological scarcity of chromium, there are still enough extractable resources to last over 100 years after $2050 .{ }^{42}$ However, the U.S. also consumed $4 \%$ of the world chromite production in 2019. ${ }^{14}$ Most of the world's resources are in Kazakhstan and southern Africa and the U.S. imports $72 \%$ of its chromium from those countries and Russia. ${ }^{14}$ Concerns over the future supply of chromium are based on the effects of labor costs, electricity costs, and other challenges to supplying countries, particularly South Africa. Additionally, waste chromium, especially if it contaminates water sources, is toxic with effects including lung cancer, ulcers, brain damage, and kidney damage. ${ }^{22}$

Traditional recycling methods. The major method of chromium recycling does not produce pure chromium but is in fact the recycling of chromium-containing stainless steel scrap into new stainless steel, which accounts for $28 \%$ of apparent consumption in the U.S. ${ }^{14}$ Chromium plating plants can recycle chromium by reducing chromium(vI), precipitating with alkalis to form solid waste, then extracting the chromium(vi) from that solid waste. ${ }^{22}$

Electrochemical recycling methods. Many methods of electrochemical recycling have been used for chromium ions, particularly chromium wastewater. Several will be discussed: electrocoagulation, electrochemical reduction, electrodialysis (ED), electrochemical ion exchange (EIX), electro-electrodialysis (EDD), electrodeionization (EDI), and a polymer-modified electrode.

In electrocoagulation cells, iron anodes have been used to produce $\mathrm{Fe}(\mathrm{II})$ which then can be used to reduce $\mathrm{Cr}(\mathrm{vI})$ to $\mathrm{Cr}(\mathrm{III}) .{ }^{23,60,61} \mathrm{Cr}(\mathrm{OH})_{3}$ and $\mathrm{Fe}(\mathrm{OH})_{3}$ both precipitate and must be separated, often including a filter. In Scheme 4 the left diagram shows a schematic for the setup of an electrocoagulation cell while the right diagram demonstrates the electrochemical mechanism of floc and sludge production particular to the conversion of $\mathrm{Cr}(\mathrm{VI})$ to $\mathrm{Cr}$ (III) and its subsequent collection. Gao et al. combined this method with electroflotation, which used the gas bubbles formed from water electrolysis to float the sludge from electrocoagulation, thus preventing the need for a filter. Power consumption was less than $1 \mathrm{~kW} \mathrm{~h} \mathrm{~m}{ }^{-3} .^{24}$

Direct electrochemical reduction can be used instead, thus not requiring the use of sacrificial electrodes as in electrocoagulation. 


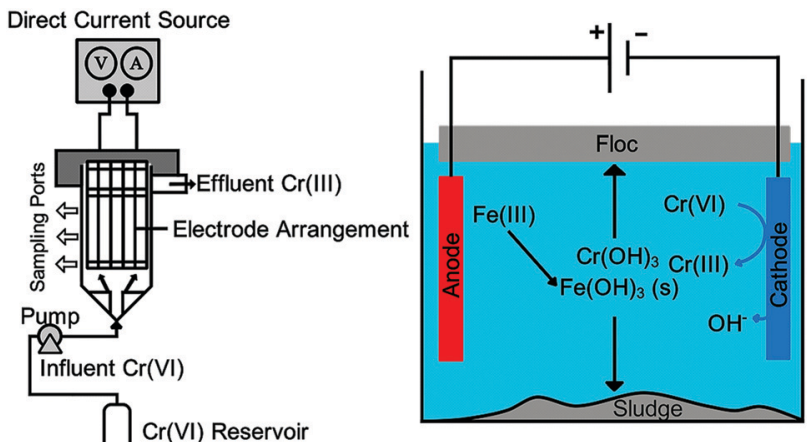

Jin et al. 2016

Scheme 4 (left) Diagram of an electrocoagulation setup demonstrating electrode placement, flows, inputs, and outputs. (right) Diagram of the mechanism of electrocoagulation, including the formation of the floc and sludge, particular to the conversion of $\mathrm{Cr}(\mathrm{VI})$ to $\mathrm{Cr}(\mathrm{III})$. (Adapted with permission from W. Jin, H. Du, S. Zheng and Y. Zhang, Electrochemical processes for the environmental remediation of toxic $\mathrm{Cr}(\mathrm{vl})$ : A review, Electrochim. Acta, 2016, 191, 1044-1055. Copyright 2016 Elsevier. ${ }^{23}$ ) Fe(III) is shown as the sacrificial metal ion to aid in coagulation but $\mathrm{Al}(\mathrm{III})$ is also known to be effective.

The process is almost identical except for the use of anodic electrodes most often made with lead dioxide coatings or noble metal oxide coatings on titanium. However, the efficiency and cost of this method is currently not favorable compared to electrocoagulation. ${ }^{23}$

Electrodialysis has been commonly used to separate $\mathrm{Cr}(\mathrm{vI})$ from water. $^{23}$ Poeton Industries (Gloucester, UK) used an electrodialysis stack of 12 lead anodes and cathodes separated by Nafion 450 to achieve a $70 \%$ reduction in water consumption and an $80 \%$ reduction in chromium loss. ${ }^{23}$

To combat the contamination of water from chromium plating and enable the reuse of the chromate ions, Basha et al. employed EIX. The setup of the system is shown in Scheme 5. When wastewater passes through the central compartment it is ionized as follows:

$$
\mathrm{K}_{2} \mathrm{CrO}_{4} \rightarrow 2 \mathrm{~K}^{+}+\mathrm{CrO}_{4}{ }^{2-}
$$

The anionic resin then adsorbs and desorbs the chromate ion, which passes into the anode chamber. Since the anode chamber is acidic, chromic acid is formed. Repeatedly flowing the wastewater through produces concentrated chromic acid solution and rinse water, which can be used again. This system achieves $98.82 \%$ removal at $12.5 \mathrm{~V}$ with an energy cost of $72.39 \mathrm{~kW} \mathrm{~h} \mathrm{~kg}^{-1}$. $^{22}$

In 2009, a glassy carbon electrode modified with poly(aniline$o$-aminophenol) was shown to remove $\mathrm{Cr}(\mathrm{vI})$ from water at pH 4-8 with a removal rate of $32.3 \%$ at $\mathrm{Cr}(\mathrm{vI})$ concentrations of $20 \mathrm{mg} \mathrm{L}^{-1}$. The $\mathrm{Cr}$ (III) is incorporated in the polymer and can be recovered by applying a cathodic potential. ${ }^{62}$

Outlook. Chromium is one of the best understood and studied metals in the electrochemical recycling of CRMs. Although little has been done with the chromium in steel, research has focused on chrome plating wastewater to help counteract hazardous

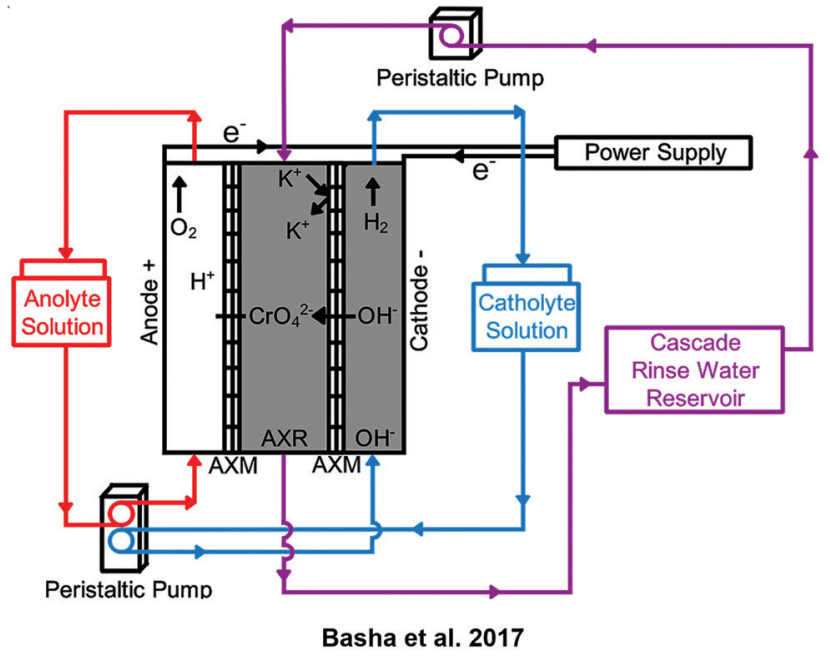

Scheme 5 An experimental setup for the removal of chromate from chromium plating-bath wastewater. Anolyte flow is depicted in red, catholyte flow in blue, and rinse water flow in purple. AXR stands for the anion exchange resin while AXM is the anion exchange membrane. (Adapted with permission from C. A. Basha, K. Ramanathan, R. Rajkumar, M. Mahalakshmi and P. S. Kumar, Management of Chromium Plating Rinsewater Using Electrochemical Ion Exchange, 2008, 47(7), 2279-2286. Copyright 2017 American Chemical Society. ${ }^{22}$ )

levels of chromium in runoff and reduce the amount of new chromium which must be obtained by this process. It is one of two minerals on this list for which an electrochemical recycling method has been used on the industrial scale to save costs and reduce waste.

\subsubsection{Lithium}

Sources and uses. The primary use of lithium world-wide is in battery technology, particularly the recognizable and common lithium-ion battery. It is also used in lubricants, polymers, ceramics, and glass. The U.S. produces most of its own lithium through a single brine operation in Nevada. Imported lithium is primarily from Argentina and Chile. Although recycling is not common, some domestic recycling of lithium from lithium-ion batteries has been done since 1992 .

Electrochemical recycling methods. Following the purification of the initial solution and precipitation of $\mathrm{Li}_{3} \mathrm{PO}_{4}$, electrodialysis can be used to produce a catholyte which, when mixed with $\mathrm{NaOH}$, produces $\mathrm{Li}_{2} \mathrm{CO}_{3}$. Overall a yield of $88 \%$ was achieved and the lithium carbonate produced met the national standard. ${ }^{37} \mathrm{~A}$ similar electrodialysis procedure (simplified schematic shown in Scheme 6) was used by Gmar et al. to collect lithium salts with $>95 \%$ purity and around $80 \%$ extraction efficiency rates with low energy consumption. Slurry electrolysis has also been used as part of a process to collect $\mathrm{Li}_{2} \mathrm{CO}_{3}$, with $99 \%$ efficiency in electroleaching and $62-77 \%$ current efficiency for electrodeposition. ${ }^{18}$

Outlook. Because of its importance in batteries, demand for lithium has increased over recent years and is expected to increase further. ${ }^{14}$ Its use in battery technologies is the driving force behind it being considered a critical mineral, since having a secure supply of lithium will be important for major electronics 


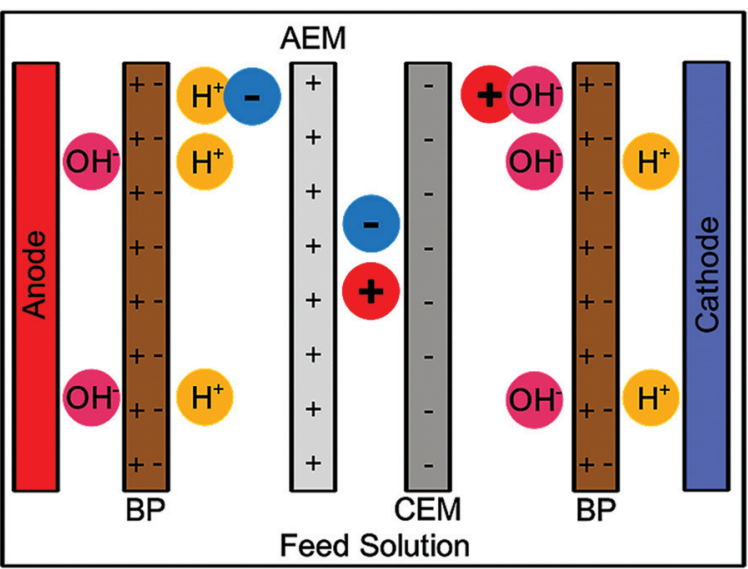

Scheme 6 Simple diagram of the setup for a bipolar membrane electrodialysis, showing the anion exchange membrane (AEM), cation exchange membrane (CEM), and bipolar membranes (BP).

industries and innovations. Electrochemical recycling is a favorable option given the efficiency of collection, usually in the form of $\mathrm{Li}_{2} \mathrm{CO}_{3}$, which can be reused immediately in new lithium-ion batteries. These methods can simultaneously collect other materials from the batteries, such as Mn, as well.

\subsubsection{Cobalt}

Sources and uses. While cobalt is not geologically scarce, ${ }^{42}$ its importance in superalloys and rechargeable batteries combined with high supply risk make cobalt a particularly critical mineral. ${ }^{14}$ Currently, $46 \%$ of the U.S. cobalt supply is used in superalloys for aircraft engines. ${ }^{11,14}$ The U.S. imports $78 \%$ of its cobalt supply, which is mostly produced in the Democratic Republic of the Congo and refined in China. Recycling from scrap accounts for $29 \%$ of reported consumption in the U.S. ${ }^{14}$ The market for cobalt is likely to grow especially due to demand for Li-ion battery development. ${ }^{11}$ However, the supply of cobalt has even recently been affected by recessions in 2001 and 2008, causing delays in mining and processing capacity expansions. ${ }^{11}$

Electrochemical recycling methods. Cobalt can be collected from superalloys through electrodecomposition in $\mathrm{HCl}$ at $70{ }^{\circ} \mathrm{C}$ with an applied current of $50 \mathrm{~A}$. The filtrate contained Co in the hydroxide form mixed with $\mathrm{Ni}, \mathrm{Cr}$, and $\mathrm{Al} .{ }^{15}$ Spent lithium-ion batteries in scrap cellular phones also contain cobalt which has been recycled via electrodeposition. The best charge efficiency of $96.90 \%$ was at $\mathrm{pH} 5.40$ and $1.00 \mathrm{~V} v s$. $\mathrm{Ag} / \mathrm{AgCl}$, resulting in a deposit of $\mathrm{Co}(\mathrm{OH})_{2} \cdot{ }^{38}$ Further study into electrodeposition directly from spent lithium-ion battery cathodes has been done with methods such as a quartz crystal microbalance technique, ${ }^{20}$ deposition onto 430 steel which was then made into solid oxide fuel cell interconnects, ${ }^{63}$ and the use of the recovered cobalt as supercapacitor material. ${ }^{64}$

Outside of superalloys, cobalt is recovered from lithium-ion batteries by leaching of the cathodic paste, separation from nickel by solvent extraction, followed by a final electrolysis step. At a current density of $250 \mathrm{~A} \mathrm{~m}^{-2}$, the electrolysis generates a Co precipitate and reduces the Co concentration in solution to $<1 \mathrm{ppm}$. At pH 4 and 6 using Al foil, 100\% current efficiency is achieved. The cobalt collected can be treated at $300{ }^{\circ} \mathrm{C}$ in air to produce $\mathrm{Co}_{3} \mathrm{O}_{4}$ which can be used to remake lithium-ion battery cathodes. ${ }^{39}$ Although lithium-ion batteries are common today, previous forms of batteries can be a source of cobalt.

Nickel metal hydride batteries were previously used in mobile phones but have been replaced by Li-ion batteries, and thus many old mobile phones with cobalt-containing nickel metal hydride batteries are being disposed. ${ }^{48,65-67}$ Santos et al. used electrodeposition at $-0.9,-1.1$, and $-1.2 \mathrm{~V} v s$. $\mathrm{Ag} / \mathrm{AgCl}$ to recover $\mathrm{CoO}$ and $\mathrm{Co}(\mathrm{OH})_{2}{ }^{48}$

Outlook. Cobalt's importance lies primarily in its use in batteries, which is where most of the efforts on electrochemical recycling have focused. Supply is scarce primarily due to geographical and political issues, thus necessitating recycling efforts. Particular attention must be paid to economical methods of recovery since the amount of cobalt in end-of-life consumer products is typically low and in combination with metals that are easier, and therefore more cost-effective, to remove.

\subsubsection{Indium}

Sources and uses. Indium is most commonly used in indium tin oxide (ITO), which is important for liquid crystal displays (LCDs), but it is also used in alloys, solders, and semiconductors. ${ }^{14}$ It is also part of copper indium (gallium) selenide (CI(G)S or CIGS) semiconductors. Zinc deposits are the most common source of indium since other mineral deposits are not economically viable for recovery of indium. ${ }^{14}$ In 2019 indium was completely imported, particularly from China, Canada, the Republic of Korea, and Taiwan, as none was recovered from ores in the U.S. ${ }^{14}$ Indium supply is a great concern to industries requiring ITO, particularly the thin-filmtransistor liquid-crystal display (TFT-LCD) industry. Indium is likely to see future demand due to its importance in fiber-optic networks and telecommunication networks. ${ }^{14}$ Indium can be recovered from TFT-LCDs containing ITO through methods such as sonication in alcohol, heating to high temperature, and crushing and grinding. ${ }^{40}$ Japan and Korea are the major countries which recover indium from ITO scrap. ${ }^{14}$

Electrochemical recycling methods. Since ITOs are the most common use of indium, development of recycling methods designed for them is critical for indium recovery. One of the challenges of recovering indium from ITOs is removing the ITO layer from the glass or plastic substrate. An electrochemical method was used to separate the two while leaving the substrate intact by applying an anodic current which caused gas evolution and separated the layers. Although the ITO could not be used as is, it can be used for other applications or the indium can be removed through an alternative method. ${ }^{68}$

Removal of ITO from the substrate can also be complicated if the substrate is already broken. Pa investigated an electrochemical discharge method to use in such a situation which does not require direct electrical contact with the ITO pieces and instead generates an electric field which separates the substrate and produces indium metal. This method can be made part of a system as shown in Scheme 7 which automates the separation process. ${ }^{40}$ Since the method avoids the use of chemicals such as acids, it helps reduce waste, pollution, and cost. 
a)

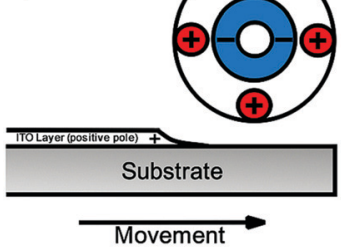

b)

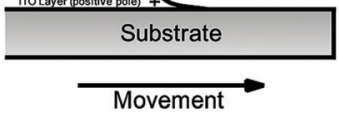

Movement
Pa 2017

Scheme 7 Setup for the use of an electrode generated electric field capable of removing the ITO layer from glass or plastic substrate recovering indium. (a) DC straight polarity mode (b) DC reverse polarity mode. DC straight polarity and DC reverse polarity can both be used, resulting in either an indium metal film or clumps of indium metal depending on the mode. The glass or plastic substrate can be either intact or broken, allowing for preservation of intact substrate and the ability to collect from broken substrate with the same technique. (Adapted with permission from P.-S. Pa, Environmentally friendly electrochemical recycling of indium from scrap ITO glass and PET, Int. J. Adv. Manuf. Technol., 2017, 89(5-8), 1295-1306. Copyright 2017 Springer Nature. ${ }^{40}$ )

Gustafsson et al. used electrodeposition to recover indium from solutions of $\mathrm{CI}(\mathrm{G}) \mathrm{S}$ in a dissolved solution from which the selenium has already been recovered. The result was an indium recovery of $98.1 \pm 2.5 \%{ }^{41}$

Outlook. The advantages of electrochemical methods for the recycling of indium primarily lie in the reduction of waste generated during the recycling process. Typically, chemical reactants such as acids or solvents must be used to separate the substrate from the ITO layer, and methods such as crushing and grinding cannot recover intact glass for reuse. Electrochemical methods can be used to selectively remove the ITO layer, thus allowing the reuse of glass or plastic components, possibly without further processing.

\subsubsection{Gallium}

Sources and uses. The United States has a 100\% import reliance for gallium, chiefly from China, the United Kingdom, Germany, and Ukraine. In fact, no domestic non-recycled gallium has been produced since $1987 .{ }^{14}$ Gallium is important in the manufacturing of integrated circuits, LEDs, photodetectors, and solar cells with integrated circuits, accounting for $73 \%$ of domestic consumption. ${ }^{14,43}$ Since integrated circuits are critical in computers and telecommunications, the economic importance of gallium is very high. ${ }^{14}$ Gallium is not geologically scarce, ${ }^{42}$ but the major source of gallium is in bauxite and as a byproduct of bauxite processing, thus complicating the supply chain. Gallium is rarely recycled. Currently there are no methods used in the U.S. to recycle old scrap, but a facility in Utah has been able to recycle new scrap. ${ }^{14}$

Electrochemical recycling methods. One of the uses of gallium is in solar cells as part of the semiconductor material copper indium gallium diselenide $(\mathrm{CI}(\mathrm{G}) \mathrm{S})$. Gustafsson et al. used electrodeposition to separate the indium, gallium, and copper from a pretreated $\mathrm{CI}(\mathrm{G}) \mathrm{S}$ solution as shown in Scheme 8. Although the gallium was separated from the other components, it remained in solution. ${ }^{41}$ Further investigations will need to be done to find a method of removing the gallium as a pure solid or as part of

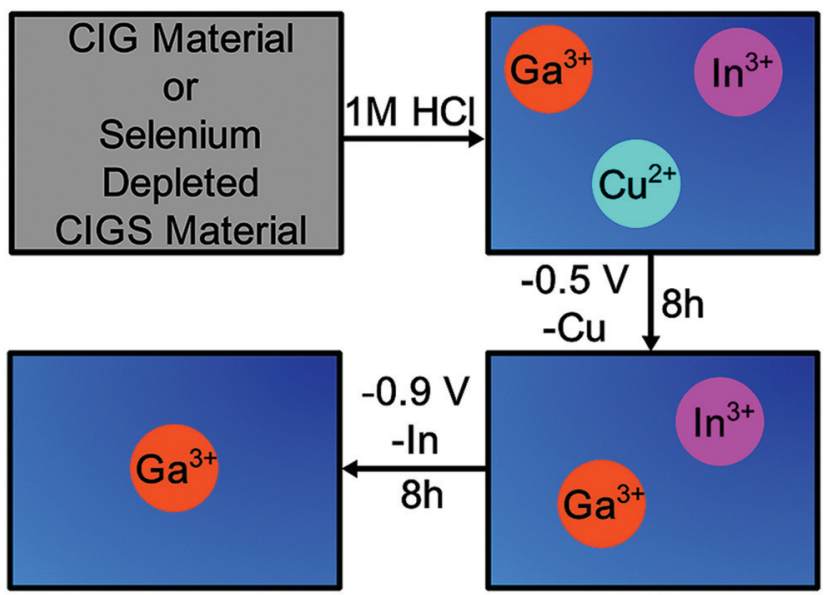

Gustafsson et al. 2017

Scheme 8 Separation process for $\mathrm{CI}(\mathrm{G}) \mathrm{S}$ involving sequential electrodeposition, first of $\mathrm{Cu}^{2+}$ at $-0.5 \mathrm{~V}$ vs. $\mathrm{Ag} / \mathrm{AgCl}$ and then $-0.9 \mathrm{~V} v \mathrm{v}$. $\mathrm{Ag} / \mathrm{AgCl}$ which results in a final solution of dissolved gallium. The dissolved gallium cannot be electroplated in aqueous solutions but may be collected in other manners.

another compound. As shown in Scheme 8, this methodology enables the efficient separation of gallium from indium and copper in a complex mixed metal waste feedstock.

Outlook. Despite its prevalence in the technologies necessary for phones, LCDs, and touchscreens, gallium has not received much attention for recycling either traditionally or electrochemically. Gallium is challenging electrochemically due to its extreme reduction potential, but the complexity of $\mathrm{CI}(\mathrm{G}) \mathrm{S}$ mixtures may make electrochemical removal of the other components an integral part in the separation and collection of gallium.

\subsection{Outlook on chemical vs. electrochemical techniques on CRM recovery}

The recovery of CRMs from solid waste highlights the importance and advantage of electrochemical methods over traditional chemical digestion. Electrochemical technologies enable processes that can extract these sought-after metallic materials from complex mixtures, whereas traditional chemical digestion or mechanicalonly processing do not afford the same kind of chemospecific targeting of the various metals. We remain forward-looking to developments in the field and look forward to research into the future concurrent recovery of both CRMs and feedstocks from organic/metal mixed media such as electronic waste.

\section{What polymers are recycled or upcycled and how?}

Plastics are currently produced on a global scale of more than 440 million tons annually ${ }^{69}$ and account for 35.37 million tons (13.2\%) of annual municipal waste in the United States, of which 26.82 million tons $\left(75.83 \%\right.$ ) are landfilled. ${ }^{70}$ Projections indicate that by mass, plastics will exceed fish in the ocean by $2050 .{ }^{69}$ Implementing improved polymer recycling methods is 
critical not only for diverting this waste, but also for mitigating the costs of polymer production and waste-water purification. Plastics for consumer products depend mostly upon fossil fuel feedstock and large energy input for production. Recycling plastics into new materials rather than using virgin feedstock can thus result in substantial energetic and monetary savings and decrease fossil fuel dependence. ${ }^{71}$ Additionally, widening the focus of polymer recycling to include common biopolymers such as cellulose and lignin can increase diversion of waste from landfills and generate useful value-added products in an eco-friendly manner. ${ }^{72}$ Whether the material in question is a polypropylene plastic bottle cap or cellulose-rich paper waste, there is much opportunity to expand polymer recycling practices.

Current recycling methods are defined as primary, secondary, tertiary, and quaternary recycling. ${ }^{69}$ Primary recycling is a closedloop mechanical process, whereby clean and pure feedstock may be melted, extruded, and remolded into a new product of the same type as that being recycled. Recycling of used polyethylene terephthalate (PET, also referred to as "poly") water bottles into new bottles is one example of primary recycling. ${ }^{71}$ Secondary recycling is also a mechanical method but is termed open-loop recycling. While secondary recycling has less stringent requirements for feedstock purity, it cannot be used to make a product of the same type as the feedstock. ${ }^{6}$ Because both primary and secondary recycling are mechanical methods, both result in degradation of plastic quality ${ }^{71}$ (caused, for example, by unwanted crosslinking or degradation and shortening of polymer chain lengths at elevated temperatures), ${ }^{69}$ limiting the number of times a given product can effectively be recycled. ${ }^{71}$ Strategies have been identified to improve the outcomes from these methods, such as solid phase polycondensation, in which a polymer sample is heated under vacuum or inert gas flow to increase molecular weight and improve mechanical properties of the recycled material. ${ }^{73}$ Despite such techniques being applied industrially in some capacity, the typical number of mechanical processing cycles a plastic can undergo is still severely limited and varies by polymer type. ${ }^{71}$ Both primary and secondary recycling methods result in an energy savings of $50 \%$ of the energy that would have been necessary to make the recycled product outputs from virgin materials. $^{69}$

Tertiary recycling, unlike the previous examples, involves chemical processing of polymer waste. ${ }^{69}$ The degradation of materials over time, as noted in primary and secondary recycling, can be avoided in tertiary recycling by breaking down plastics to monomeric or oligomeric components for use in new polymerization reactions or as separate chemical products. Pyrolysis, or the application of high temperatures and catalysts to induce depolymerization, is one of the most common chemical methods in use. ${ }^{71}$ Due to the high energy input associated with such processes, tertiary recycling is not frequently implemented on an industrial scale. Selectivity presents another issue. Polymer waste feedstock consists of molecules of varying length, molecular weight, branching, and crosslinking, making it difficult to obtain well-defined products. ${ }^{69}$ This issue is further complicated by the fact that waste consumer plastics contain a variety of other substances, including pigments, plasticizer additives that improve mechanical properties, other plastics or materials from the end-oflife product being recycled, and contaminants from other waste streams. Implementation of techniques that are mild, selective, robust to contaminants, and less energy-intensive is a strongly desired research goal.

Finally, quaternary recycling is the burning of waste materials for energy recovery. ${ }^{71}$ This method has the lowest feedstock quality requirements but recovers only half as much energy as that saved by mechanical methods and creates additional environmental impact in the form of $\mathrm{CO}_{2}$ emissions and harmful pollutant byproducts. ${ }^{69}$ In the United States, approximately $15.8 \%$ of plastic municipal waste undergoes quaternary recycling. ${ }^{70}$ Between the combusted and landfilled fraction of plastic wastes in the United States and the limitations of current mechanical and tertiary recycling methods, there is much room for improved processes.

With the wealth of electrochemical methods established for the manufacturing of chemicals, the renaissance of organic synthetic methods, ${ }^{74}$ and the developing efficient electrochemical recovery of CRMs, it stands to reason that such methodologies can translate to the chemospecific cleavage of chemical bonds from the framework of polymeric solid state materials. Challenges remain related to mass transfer from solid to the liquid phase and selectivity, separations, and overall efficiency of the processes. However, the significant advantages of electrochemical methods in reducing corrosive and hazardous redox reagents bring forth new avenues in the mining and recovery of valuable materials from organic solid waste as described in the following sections. Electrochemical methods additionally are an atom-economical, sustainable way of doing so.

\subsection{Overview of electrochemical recycling and upcycling of polymers}

With ever-increasing global plastics production and domestic waste generation, the need to recycle polymer waste streams is a critical goal. Recycling methods for these materials, from hydrocarbon-based consumer plastics to food and paper wastes containing biological polymers such as cellulose, are currently employed for only a fraction of wastes generated. While the need for effective recycling of manmade polymers is well known, even food and paper wastes which are theoretically biodegradable are unable to degrade as designed under anaerobic conditions of landfills. Under these conditions, they produce methane, a potent greenhouse gas if simply relegated to the trash. Although recycling offers a greener and often value-added approach, it is complicated by complex waste mixtures and the rapid quality degradation of plastics recycled by mechanical methods. However, continued development of electrochemical recycling methods may offer the prospect of generating revenues from the recovery of monomers from waste polymer streams or new methods to produce valuable chemicals from otherwise landfilled materials. The former development may economically incentivize the effective recycling of these waste materials, whilst the latter may allow plastics to be entirely broken down and repolymerized into fresh material. This circumvents the quality losses caused by repeated mechanical recycling and helps to truly close the loop on a circular economy. 
Electrochemical conversions have been explored for biopolymers including cellulose, lignin, and chitosan. Diversion of landfill waste and generation of value-added products are key goals for this class of polymer. For example, cellulose may be depolymerized into various sugars and carboxylic acids, just as lignin may be depolymerized into vanillin and its derivatives. Biopolymers may also be electrochemically functionalized, offering the possibility of renewed applications without the need for depolymerization.

Electrochemical conversion of the manmade polymers polypropylene (PP), nylon, and poly(ethylene terephthalate) (PET) is also discussed. Although electrochemical recycling of hydrocarbonbased polymers like PP is often even more challenging, some promising preliminary research shows depolymerization of PP into fuels like hydrogen and light hydrocarbons. Finally, PET has been found to be effectively broken down into terephthalic acid, and ethylene glycol, which can be repolymerized into new PET and directly contributes to the goal of a circular economy.

4.1.1 Cellulose. Cellulose, the single most abundant biopolymer, comprises up to $47 \%$ of wood and is generated in the environment at an estimated rate of $1 \times 10^{10}$ tons annually. ${ }^{75}$ Cellulose both presents an immense opportunity for chemical

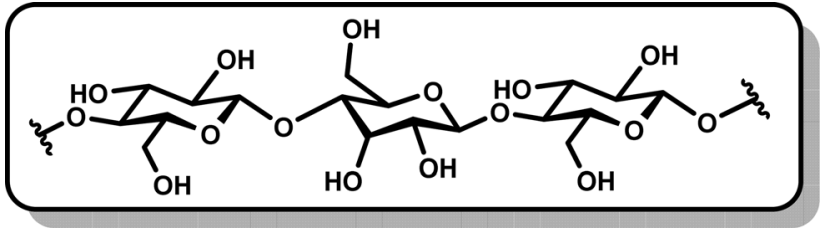

Fig. 2 Structure of cellulose showing linear chain of $\beta$ - $(1 \rightarrow 4)$-linked glucose units.

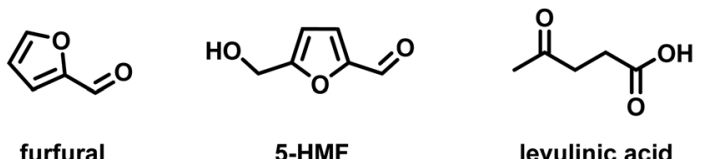

Fig. 3 Examples of products sought from depolymerization of cellulose. upcycling and contributes substantially to landfilled waste. In 2017, the EPA found that paper and paperboard accounted for $13.1 \%$ of landfilled municipal solid waste, wood $8.7 \%$, and yard trimmings $6.2 \%$. In total, 39 million tons of annually landfilled waste consists largely of cellulose. ${ }^{70}$ As illustrated in Fig. 2, cellulose is made up of linearly connected glucose sugar units connected by $\beta-(1 \rightarrow 4)$ linkages. Unlike highly branched biopolymers such as lignin, cellulose exhibits a high degree of crystallinity. Due to its ubiquity, cellulose has generated much interest both in functionalizing the polymeric form for new applications, ${ }^{76}$ using it as a carbon source for new materials, ${ }^{3,77}$ and in breaking it down to generate useful products such as sugars, carboxylic acids, polyols, and furans, some examples of which are depicted in Fig. $3 .^{78-81}$

Several interesting methods of transforming cellulose into new materials have been reported, including uses in electrodes and electrolytes for lithium-based batteries. ${ }^{3,77,82}$ However, these methods frequently involve chemical transformations or pyrolysis rather than electrochemical methods. Similarly, traditional cellulose depolymerization efforts typically incorporate pyrolysis at extreme temperatures of above $500^{\circ} \mathrm{K}^{83}$ or chemical methods with harsh conditions or modest yields. ${ }^{79,80}$ Forcing depolymerization conditions are often necessitated by the high crystallinity and low solubility of cellulose in both aqueous and organic solvents, ${ }^{84}$ but harsh conditions such as high $\mathrm{pH}$ have been observed to break down desired depolymerization products. ${ }^{81}$ Milder enzyme-based reactions show some benefits in these areas but often suffer from high cost. ${ }^{84}$

Electrochemical techniques have successfully avoided issues of high temperature and cost both in functionalizing cellulose and in depolymerizing it. The degree of polymerization (DP) indicates the number of monomer units in a polymer and is often used as a measure of success for depolymerization methods. As illustrated in Fig. 4, Meng and colleagues found that cotton cellulose could be reduced from an average initial DP of 1100 to a final DP of 367 in 8 hours in a room-temperature $0.5 \mathrm{M}$ sulfuric acid electrolysis, with a maximum yield of 5-hydroxymethylfurfural (5-HMF) of $1.8 \%$ under optimized conditions. ${ }^{78}$ With modifications for materials applications, Isogai and colleagues also successfully implemented an electrochemically assisted procedure at ambient temperature. ${ }^{85}$ Using 2,2,6,6-tetramethylpiperidine1-oxyl (TEMPO) radicals with a 4-acetamido group as an oxidizing

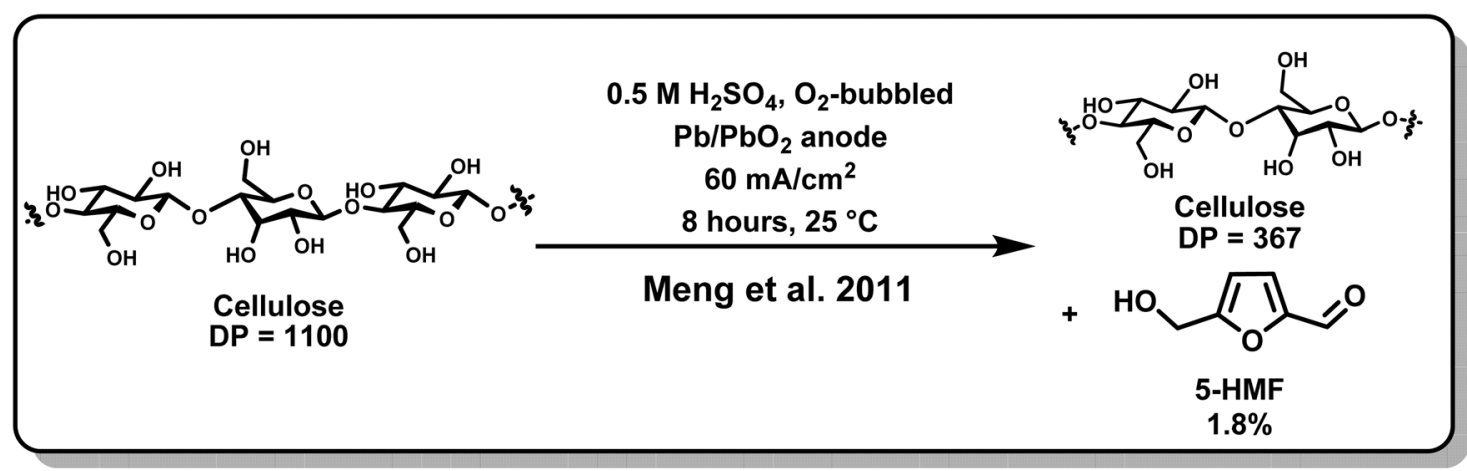

Fig. 4 Electrochemical depolymerization demonstrated by Meng and colleagues. ${ }^{78}$ 
agent, the latter work demonstrated oxidation of cellulose in the form of viscose rayon fiber to increase carboxylate and aldehyde content without losing the original surface morphology, a development that may have implications for uses in medical applications as well as household products.

Although the results of these recent works show promise, investigations of electrochemical methods for cellulose recycling require further development for large scale deployment. While electrochemical techniques already frequently excel in the areas of mild conditions and ease of operation, further work is needed to establish techniques that are suitable for industrial scale-up. Improved yields for well-defined products will be a focus in future work that seeks to depolymerize cellulose electrochemically.

4.1.2 Lignin. Following cellulose, lignin is the second most abundant plant biopolymer. ${ }^{86}$ As a major structural component in the cell walls of vascular plants, ${ }^{72}$ lignin is produced as a significant waste product of both paper and ethanol production on a megaton scale annually. ${ }^{87}$ Structures of the monomeric precursors of lignin, sinapyl alcohol, $p$-coumaryl alcohol, and coniferyl alcohol, are given in Fig. 5. The overall structure of lignin, as shown in Fig. 6, includes a branching aromatic backbone with sinapyl, -coumaryl, and coniferyl units connected through a variety of $\mathrm{C}-\mathrm{C}$ and $\mathrm{C}-\mathrm{O}-\mathrm{C}$ linkages, which are present in varying amounts depending upon the lignin source. ${ }^{88}$ Lignin structure also varies with the extraction or pulping method applied to its plant source. The widely used Kraft process, for instance, adds carbohydrate linkages and alters terminal groups. ${ }^{72}$ Although lignin and its derivatives have a host of uses in polymeric form, from animal feedstock binder to concrete additives, ${ }^{89,90}$ much of the total amount of waste lignin is currently burned as a fuel. ${ }^{88}$ For many industrial producers of lignin waste, combusting this byproduct is appealing for its well-established technology and cost-effectiveness. ${ }^{91}$ However, as an alternative to this emission-heavy process, the unique aromatic backbone of lignin has generated much interest in depolymerization chemistries to create higher-value aromatic monomeric and oligomeric products.

Chemical lignin depolymerization methods consist mainly of three broad classes: hydrolytic, oxidative, and reductive depolymerization. Hydrolysis typically results in low yields and complicated product separation, ${ }^{92}$ and chemical oxidative depolymerization methods often oxidize products too far (producing $\mathrm{H}_{2} \mathrm{O}$ or $\mathrm{CO}_{2}$ ) and suffer from repolymerization, lowering yields. ${ }^{93,94}$ Although certain reductive chemical catalytic techniques have shown promising results for lignin depolymerization, they often still necessitate relatively harsh conditions.

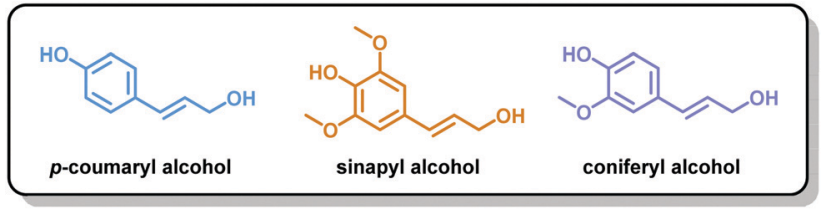

Fig. 5 Structures of the three lignin precursors: p-coumaryl alcohol, sinapyl alcohol, coniferyl alcohol.
Reductive catalytic fractionation (RCF) of lignocellulose waste streams, for example, offers a promising alternative to traditional pulping methods like the Kraft process and can be used to simultaneously convert lignin to low molecular weight products at $180-250{ }^{\circ} \mathrm{C}$ with high efficiencies by cleaving $\beta-\mathrm{O}-4$ and $\alpha-\mathrm{O}-4$ linkages. ${ }^{95,96}$ However, such temperature demands are still fairly high, and many reductive methodologies rely upon high pressures of $\mathrm{H}_{2}$ on the order of several $\mathrm{MPa}^{97}$ or noble metal-based heterogeneous catalysts to achieve the highest yields. ${ }^{95,98,99}$ Chemical techniques thus often require either high temperature or pressure, and few options remain that avoid the energetic and financial expense of both problems. Electrochemical methods are therefore uniquely positioned to avoid the necessity of intense energy inputs to pressurize or heat reaction systems if suitable methods are employed, and thus research into designing effective electrochemical techniques may hold a promising future for lignin depolymerization applications.

Electrochemical depolymerization methods circumvent many issues of traditional chemical methods, enabling operation at ambient temperature and pressure, often without the need for pre-treatment or additives. In reductive chemistries, electrocatalytic methods additionally offer improved selectivities and better process safety over catalytic hydrogenation. ${ }^{72}$ Oxidative electrochemical methods also offer the benefit of mild conditions but typically suffer from lower selectivities and low yields. ${ }^{72,86,100,101}$ Oxidations often install new functional groups like carboxylic acids, but overoxidation remains a problem, with phenolic products often being oxidized to $\mathrm{CO}_{2}$ via quinone intermediates. ${ }^{102}$ Both varieties of electrochemical conversion suffer from the siphoning of current to the unwanted side reactions of cathodic hydrogen evolution or anodic oxygen evolution in aqueous solutions due to the solvent window limitations of water. Additionally, the complex structure of lignin inherently results in mixtures of various products upon depolymerization, as evidenced by several procedures presented in Fig. 6, such as the work of Zhu et al. (Fig. 6C), ${ }^{86}$ Stiefel et al. (Fig. 6D), ${ }^{102}$ and Dier et al. (Fig. 6E). ${ }^{103}$ Altogether, these problems introduce the need for complicated workup procedures and losses in faradaic efficiency toward depolymerization.

Researchers have addressed these limitations with a variety of approaches. Schmitt and colleagues employed a basic anion exchange resin in oxidative electrolyses to selectively adsorb vanillin and small amounts of acetovanillone side product, leaving behind unreacted lignin and side products without the need for extensive workup (Fig. 6F). ${ }^{104}$ This allowed for the efficient, selective collection of vanillin simply by rinsing the resin with acid, avoiding complex product mixtures typically associated with poor selectivity. The selective product adsorption could potentially also allow for the retrieval of vanillin when a variety of reaction products are present, including products associated with contaminants. This methodology thus may lower quality and purity requirements for lignin waste subjected to the treatment, as the desired vanillin product would not need to undergo complex separations from side products resulting from other types of polymer waste in the input. Stiefel et al. similarly introduced a continuous separation of products via nanofiltration membrane in a flow cell, sequestering products 

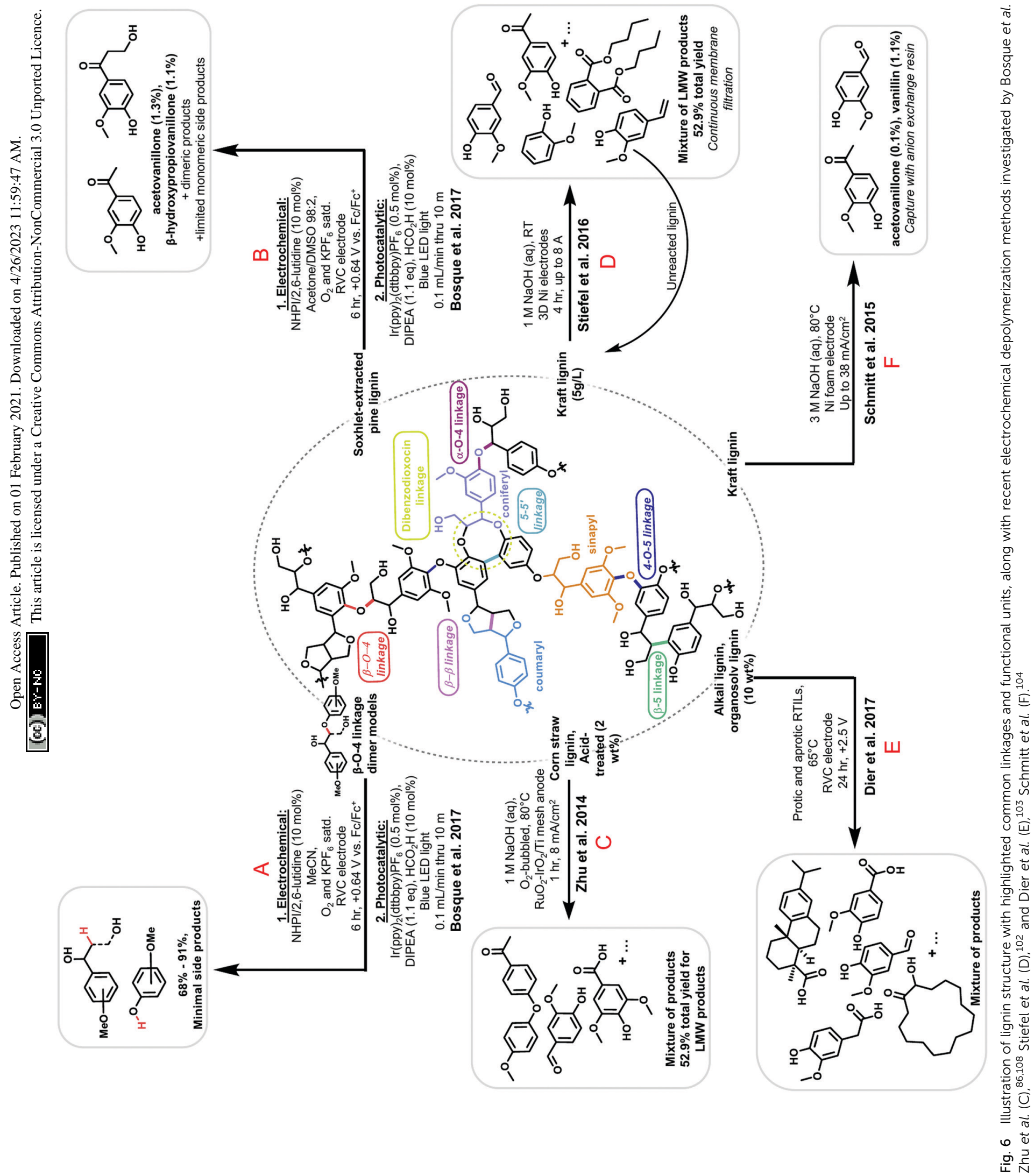


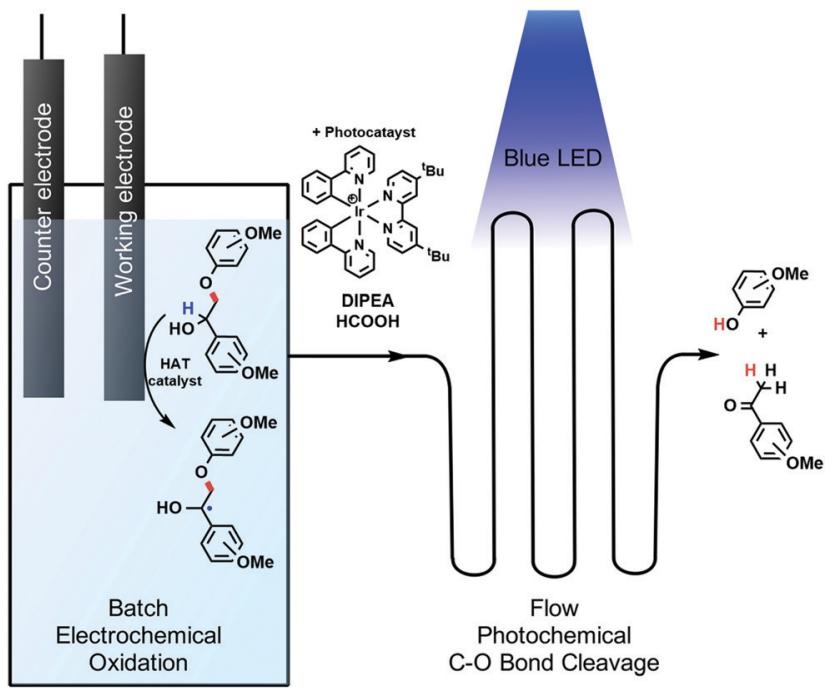

Bosque et al. 2017

Scheme 9 Combined electrochemical/photochemical lignin depolymerization method on model compounds, showing first the batch electrochemical oxidation to selectively abstract benzylic hydrogens (blue) and subsequently the cleavage of $\mathrm{C}-\mathrm{O}$ bonds from $\beta-\mathrm{O}-4$ linkages (color-coded in red) in a flow photochemical setup in the presence of Ir-based photocatalyst. ${ }^{107}$

while leaving unreacted lignin in the reaction vessel for further decomposition (Fig. 6D) ${ }^{102}$ The separations employed by both groups also mitigate the issue of product overoxidation by quickly removing desirable products from the oxidizing environment. The latter work also addressed the issue of low yields by illustrating that a $93 \%$ reduction in the starting material lignin molecular weight could be achieved in under 4 hours with high surface area nickel electrodes.

Other groups have addressed the need for a wider solvent window by using room-temperature ionic liquids (RTILs) for dual use as both solvent and electrolyte. ${ }^{103,105,106}$ The work of Dier et al. constitutes one such example (Fig. 6E). ${ }^{103}$ This approach has found success, circumventing the lignin solubility issues often associated with non-aqueous systems and providing the ability to disrupt lignin-hemicellulose networks for lignin samples in native biomass through solvation. ${ }^{106}$ However, RTIL systems come with the tradeoff of increased solvent cost.

Finally, Bosque and colleagues investigated a unique alternative to all of the above processes: batch electrocatalytic oxidation followed directly by reductive, photocatalytic fragmentation in a flow system (Fig. 6A and B). ${ }^{107}$ The electrochemical step made use of a hydrogen atom transfer (HAT) catalyst, $10 \mathrm{~mol} \%$ 2,6-lutidine with $N$-hydroxyphthalimide (NHPI), to selectively abstract hydrogen atoms from benzylic $\mathrm{C}-\mathrm{H}$ bonds on lignin and model compounds upon the application of an oxidizing potential from a reticulated vitreous carbon (RVC) working electrode. The subsequent addition of an iridium-based photocatalyst, formic acid, and diisopropylethylamine directly to solution and transfer of the system to a flow system irradiated with blue LED light revealed good efficiency for the cleavage of $\mathrm{C}-\mathrm{O}$ bonds associated with $\beta-\mathrm{O}-4$ linkages. Scheme 9 illustrates this process for the case of model compounds investigated in the research.

As shown in Fig. 6A and B, this method was found to work for both model compounds and native lignin and carried the advantage of not requiring any workup between the batch step and the flow step. Native lignin still produces relatively low yields in this process but shows good selectivity for acetovanillone and $\beta$-hydroxypriopiovanillone. In all, this approach demonstrates that photochemistry may be employed as a complementary tandem method to electrochemical techniques for selective depolymerization, and shows promise as an alternative to traditional chemical methods. Selected recent works in electrochemical lignin depolymerization are presented in Fig. 6, although many other methods have been investigated.

Lignin is among the most developed of the polymers discussed here in terms of research efforts toward electrochemical depolymerization. The above methods are promising steps toward effective lignin recycling, but many of the above approaches excel in some areas while leaving other problems unaddressed. The first two methods provide compelling solutions for the prevention of product oxidation but occur at low lignin concentration and do not address efficiency issues associated with having an aqueous solvent. RTILs avoid the issue of oxygen or hydrogen evolution and enable higher lignin concentrations for faster processing of large quantities of lignin waste, but they require improvements in yield and carry the burden of higher cost and high viscosity, with the potential to cause solution stirring problems. ${ }^{103}$ For these systems to reach industrial readiness levels, further work will focus on optimizing solutions to the above problems simultaneously and ensuring that the processes can scale up in a way that is chemically efficient and cost-effective.

4.1.3 Chitosan. Synthesized industrially from partial deacetylation of crustacean shell chitin with concentrated $\mathrm{NaOH}$ or chitin deacetylase as shown in Fig. $7{ }^{109}$ chitosan also has relevance for sustainable polymer applications. Chitosan represents an important recycling pathway for shell waste from seafood processing plants, which largely consists of chitin and is generated on an estimated

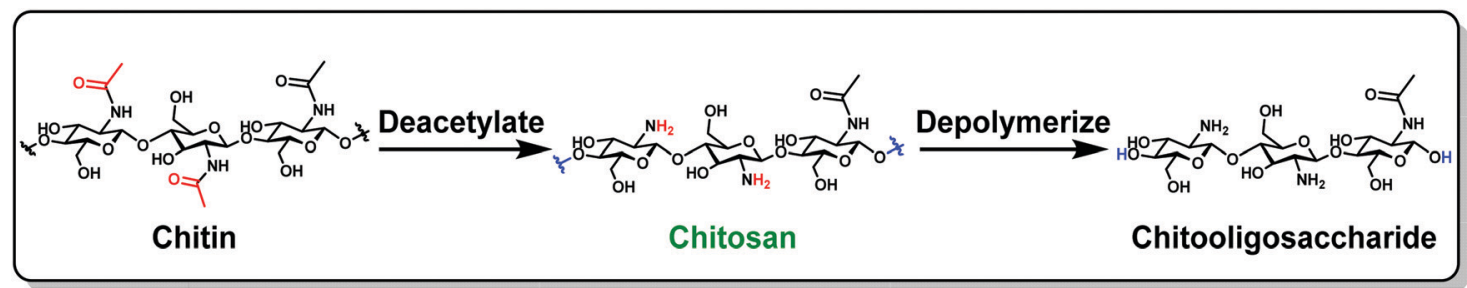

Fig. 7 Structures and relationships between chitin, chitosan, and chitooligosaccharides. ${ }^{109}$ 


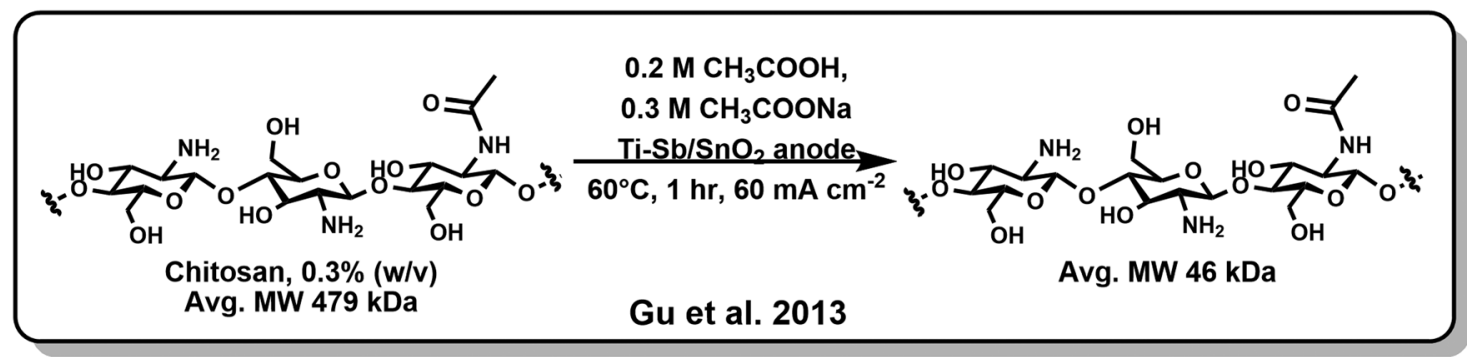

Fig. 8 Electrochemical depolymerization of chitosan reported by Gu et al. ${ }^{117}$

global scale of over 6.6 million tons annually. ${ }^{110-112}$ With observed antimicrobial properties, improved solubility compared to chitin, and desirable physical properties, chitosan is produced for use in everything from water treatments to cosmetics. ${ }^{112,113}$ New uses for chitosan and chitosan-derived materials continue to emerge; for example, Deng et al. have described a method for efficient electrospinning of chitosan/poly(ethylene oxide)/lauric arginate materials to form antimicrobial films, which may be beneficial in replacing traditional polymer food packaging and enabling minimal use of preservatives. ${ }^{114}$

Although chitosan may be considered an upcycled material in its own right due to its relationship to chitin (as shown in Fig. 7), it also has the potential to be recycled electrochemically into chitooligosaccharides (COS). COS have a similar structure to chitosan but substantially lower molecular weight, with a DP of only between 2 and 20, and are therefore desirable for a variety of biological applications requiring solubility and biocompatibility. ${ }^{113}$ Lower molecular weight chitosan with unchanged overall structure and functionalities is strongly desired, as these smaller chemical species have shown improved utility in applications ranging from antimicrobial coatings ${ }^{115}$ to encapsulation of active ingredients in medical products. ${ }^{116}$

As illustrated in Fig. 8, Gu and colleagues demonstrated electrochemical depolymerization of chitosan in an aqueous acetic acid/sodium acetate buffered solution at a scale of $250 \mathrm{~mL}$ of $0.3 \%(\mathrm{w} / \mathrm{v})$ chitosan using a $\mathrm{Ti} / \mathrm{Sb}-\mathrm{SnO}_{2}$ anode. ${ }^{117}$ Significant depolymerization was observed, with the average chitosan molecular weight decreasing from $479 \mathrm{kDa}$ to $46 \mathrm{kDa}$ after 60 minutes of reaction time at $60{ }^{\circ} \mathrm{C}$ under a constant applied current density of $60 \mathrm{~mA} \mathrm{~cm}^{-2}$. This performance surpassed that of previous work using a $\mathrm{Ti} / \mathrm{TiO}_{2}-\mathrm{RuO}_{2}$ electrode. ${ }^{118}$ However, the electrodes investigated in these applications still degrade quickly in the reaction conditions, invalidating the methods for long-term use. ${ }^{113}$ While these developments offer promising first steps, much further development is still needed to achieve an electrochemical recycling method that is ready for industrial use.

However, other avenues of chitosan depolymerization making use of electricity as a reagent have been pursued with preliminary success. Research has found that treatment of chitosan with pulsed electric field (PEF) methods also resulted in substantial decrease of the average chitosan molecular weight, with greater decreases observed for greater applied voltages. ${ }^{119}$ Such techniques apply an electric field to a sample in solution, producing hydroxyl radicals and possibly oxidizing the compounds at the glycosidic

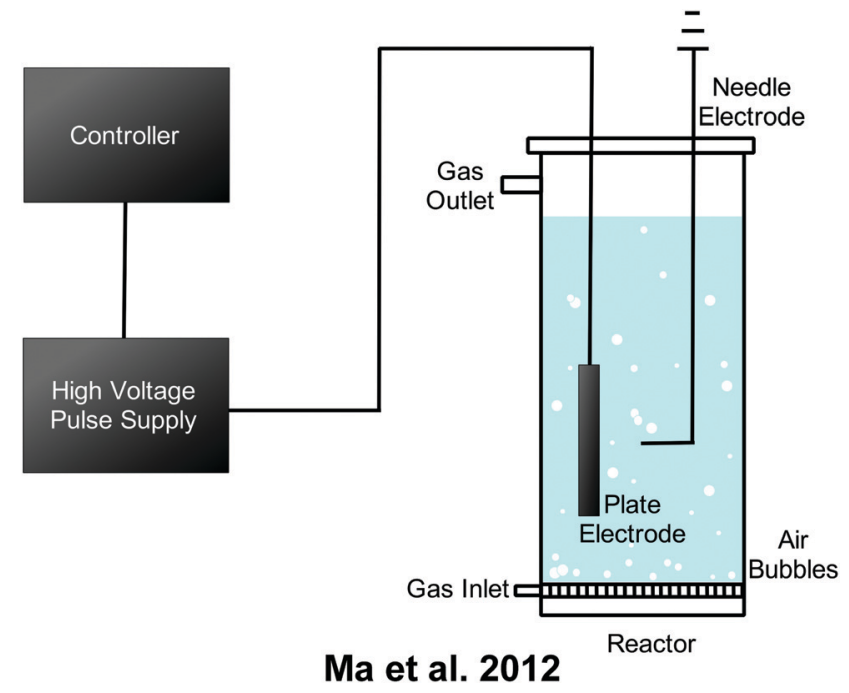

Scheme 10 Schematic representation of the SSP method carried out by $\mathrm{Ma}$ et al. and adapted from their work. ${ }^{121}$ Licensed under CC BY 3.0.

linkages. In the methods of Luo et al., samples of chitosan were dissolved in $10 \%(\mathrm{v} / \mathrm{v})$ acetic acid and pumped through a PEF system consisting of two copper plates separated by a Teflon separator at a flow rate of $100 \mathrm{~mL} \mathrm{~min}^{-1}$. A square-wave pulse of $20 \mu \mathrm{s}$ duration and $1000 \mathrm{~Hz}$ frequency was then applied at various voltages. At an applied field of $25 \mathrm{kV} \mathrm{cm}^{-1}$, the initial chitosan average molecular weight of $2.81 \times 10^{5} \mathrm{kDa}$ was reduced to $1.52 \times 10^{5} \mathrm{kDa}$, indicating promising results for a process that could reasonably be scaled up.

Similarly, solution plasma process (SPP) has been found to generate plasma and reactive, oxidizing species in situ using electrical currents ${ }^{120}$ for the successful depolymerization of chitosan. ${ }^{121} \mathrm{Ma}$ et al. found that chitosan samples of average starting molecular weight $1138.11 \pm 0.20 \mathrm{kDa}$ could be dissolved in a $2 \% \mathrm{H}_{2} \mathrm{O}_{2}$ solution of $0.3 \mathrm{wt} \%$ chitosan and broken down to an average molecular weight of $16.25 \pm 0.58 \mathrm{kDa}$ in 180 minutes using this method. Throughout the 180 minutes, a high voltage pulse generator applied pulses of maximum voltage $60 \mathrm{kV}$ to generate plasma in the aerated $0.3 \mathrm{wt} \%$ chitosan solution, as shown in Scheme 10.

4.1.4 Polypropylene. Several methods of electrochemically recycling biopolymers have been discussed, but non-biodegradable plastics present a larger challenge in many ways. As discussed, 35.37 million tons of plastics are generated in municipal waste in 
<smiles>CCCCC(C)(C)CC</smiles><smiles>CC(C)CC(C)C(C)C</smiles>

\section{Polyethylene Polypropylene}

Fig. 9 Structures of common hydrocarbon polymers: polyethylene, polypropylene and polystyrene.

the United States alone, the majority of which is either landfilled, released to the environment, or burned. ${ }^{69,70}$ Because the plastics found in consumer waste degrade on an extremely slow timescale, diverting this waste is of even greater importance. Polypropylene (PP) is one such plastic that is significant for its widespread use in consumer products. PP additionally makes up part of the commonly used class of hydrocarbon-based plastics, and recycling efforts made toward PP may therefore have important implications for this class generally. The structures of PP and other hydrocarbon-based plastics are given in Fig. 9.

Among existing non-electrochemical methods for this class of polymers, mechanical recycling and high-temperature tertiary recycling methods are most frequently employed. Mechanical recycling methods are often limited by the poor quality of recycled plastic mixtures. Chemical recycling methods, however, can overcome this limitation, and have the potential to recover useful chemicals from used plastics. One of the most commonly employed methods of chemical recycling is the process of pyrolysis, which is also applied to many other kinds of polymers and is a superior alternative to landfilling, despite its high energy input required. In the case of polypropylene plastic, a pyrolysis unit can be used to convert plastic waste to a liquid oil made of smaller hydrocarbon chains, sometimes called "pyrolysis oil". ${ }^{122}$ Additional methods of recycling polypropylene that involve the regeneration of the original polymer have also been explored. ${ }^{123}$ Such methods produce polymers of slightly lower quality, but with many of the original properties of the starting material, and these recycled polymers have seen applications in wood-plastic composites (WPCs) and polymer blends. ${ }^{123}$

Another interesting example of polypropylene recycling to obtain a non-fuel product involves the upcycling of waste PP into graphene, by Gong et al. ${ }^{124}$ A challenge previously limiting synthesis of graphene from waste materials is that waste plastics typically degrade into multiple products, including aromatics, light hydrocarbons, and long-chain olefins. Selective transformation of

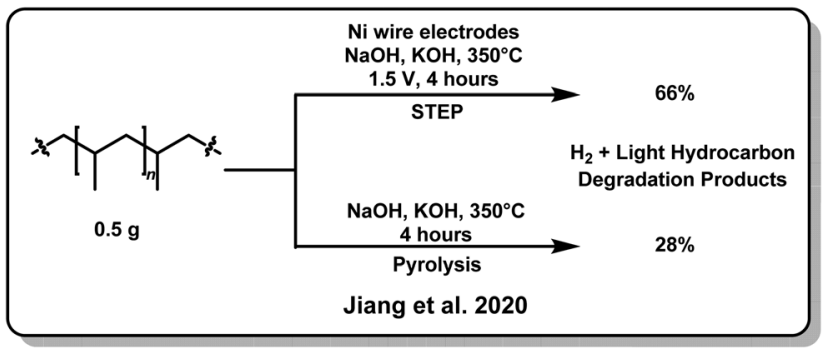

Fig. 11 Solar-thermal-electrochemical process STEP (top) and pyrolysis (bottom) on waste polypropylene. ${ }^{129}$

waste plastic is needed to obtain only the aromatic and hydrocarbon products, as those are the products that can yield graphene.

In order to achieve this selectivity, organic montmorillonite (OMMT) was used as a catalyst (Fig. 10). ${ }^{124}$ Polypropylene waste from a local company was broken down into granules, underwent pyrolysis at $700{ }^{\circ} \mathrm{C}$ on an OMMT surface, and was separated from the OMMT and purified using $\mathrm{HF}$ and $\mathrm{HNO}_{3}$. The graphene product was characterized using SEM and TEM, and was found to have a wrinkled morphology, similar to graphene "flakes" found in other systems. ${ }^{125}$ The product was found to have no amorphous carbon or other impurities, and the percent yield (which was calculated by comparing the amount of carbon in the starting waste mixture to the amount of carbon in the graphene product) was $83 \%$.

Solar and electrochemical energy have also been used in tandem in material recycling, representing a more sustainable variation of high-temperature thermal recycling. The solar-thermalelectrochemical process (STEP) is depicted in Fig. $11 .^{126}$ As discussed in previous examples, pyrolysis, which is the most employed method of breaking down plastics, is extremely high energy, endothermic, requires temperatures up to $500{ }^{\circ} \mathrm{C}$, and often requires a catalyst. ${ }^{126-129}$ STEP uses solar energy to reduce that energy barrier and obtain higher yields with less harsh conditions. The process works by coupling oxidative carboncarbon bond breaking at the anode with hydrogen evolution at the cathode. The electrochemical steps (powered by solar power from the solar panels), coupled with the standard thermochemical carbon-carbon bond breakage from pyrolysis, significantly lowers the overall thermal energy input required.

Jiang et al. found that, by linking a solar panel to a photovoltaic (PV) module, they could use STEP to break down PP waste into hydrogen gas and light hydrocarbons. ${ }^{129}$ A nickel wire electrode was used, and a mixture of $\mathrm{NaOH}$ and $\mathrm{KOH}$ was used as the electrolyte. A voltage of $1.5 \mathrm{~V}$ was applied for 4 hours, at a temperature of $350{ }^{\circ} \mathrm{C}$, via a solar to thermal unit

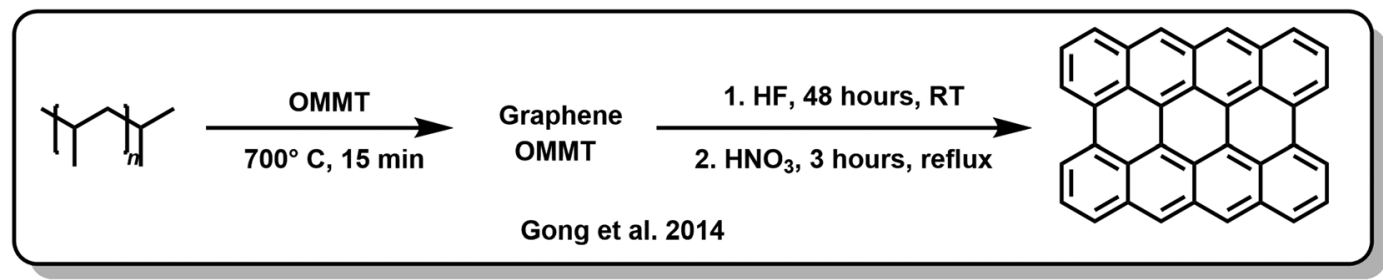

Fig. 10 Synthesis of graphene from waste polypropylene over organic montmorillonite (OMMT). ${ }^{124}$ 


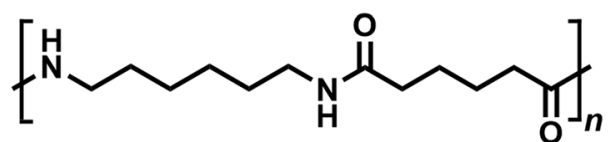

Nylon 6,6

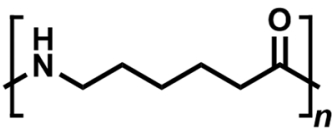

Nylon 6

Fig. 12 Structures of the two most common nylon polymers, nylon 6 and nylon 6,6.

(heat concentrator). The maximum conversion obtained was $66.64 \%$, which compares favorably to the maximum obtained through pyrolysis, which was $28.37 \%$. In addition to the superior yield, STEP also has the potential to be significantly less expensive than pyrolysis. While the main cost of pyrolysis is the generation of heat, which is a reoccurring expense, the primary cost of STEP is simply obtaining the materials for the setup (the solar concentrators, solar cells, and reactors). Once this initial cost is met, the energy to break down the plastics comes from the sun, making STEP significantly less expensive (and more sustainable) in the long run.

The successful breakdown of PP through STEP represents a promising solution to the problem of hydrocarbon plastic waste, where few chemical handles exist due to lack of functionality. Future steps should include optimizing the process for other hydrocarbon-based polymers as well, and increasing conversion to a specific, desired product (only hydrogen gas, or only light hydrocarbons) as opposed to the inhomogeneous product mixtures that are currently produced.

4.1.5 Nylon. Since their discovery in 1931, nylon 6 and nylon 6,6 (Fig. 12) have been some of the most commonly used artificial fibers, most often in carpets. ${ }^{130}$ To date, an estimated $65 \%$ (or 2 billion pounds) of carpet fibers are comprised of nylon. The average lifetime of a carpet is only 8-12 years, but nylon can be recycled repeatedly without losing its quality, so it would be beneficial to have an inexpensive way to recover the nylon from other materials in end-of-life carpet. ${ }^{131}$ However, carpet recycling is difficult for several reasons, including the large amount of debris that inevitably accumulates in carpet fibers after use (increasing their weight by an average of 30\%), and the inhomogeneity of carpet materials as a whole.

The most desirable (and commonly utilized) method of carpet recycling is depolymerization, as it is the only method that does not cause a decrease in quality of the final product. However, it is more expensive, and yields are not always high. Useful products that can be obtained from depolymerization reactions include caprolactam (the monomer for nylon 6) and

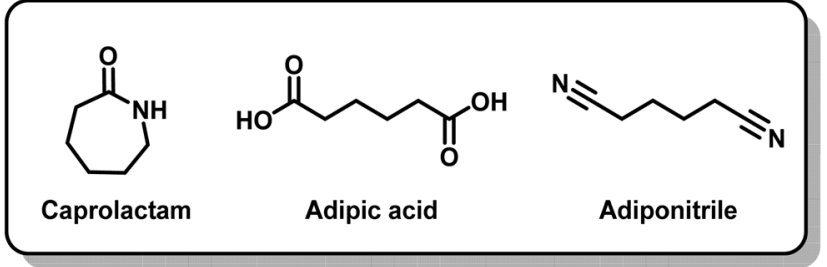

Fig. 13 Structures of caprolactam along with adipic acid and adiponitrile, monomers for nylon 6 and nylon 6,6 , respectively. adiponitrile and adipic acid (two of the monomers for nylon 6,6) (Fig. 13). The depolymerization reaction is endothermic, and often done at high pressure and high temperature, with steam as a "carrier" removing the monomer as it is generated. Usually, the majority product is caprolactam. Often, reactions are aided by an acid (ortho-phosphoric acid or para-toluenesulfonic acid) or base (carbonates or hydroxides) catalyst, which allows for higher yields (above 90\%) without requiring as high temperatures.

Aliphatic acids have now been shown to mediate the electrochemical depolymerization of nylon. Acids acids used are typically acetic acid or propionic acid, and the acid is typically used as a solvent, to ensure that there is at least 1 eq. of acid per repeat unit of the polymer. The preferred temperature is between $200-250{ }^{\circ} \mathrm{C}$. Additionally, traditional oxidation agents can be used, such as hydrogen peroxide, $\mathrm{O}_{2}$, or exposure to air with an oxidative catalyst.

The most efficient example of electrochemical oxidation, from Moran et al., led to a $70 \%$ yield of adipic acid (Fig. 14). ${ }^{132}$ This compares favorably to non-electrochemical methods, which had yields ranging from $0.33-36.2 \%$. In this method, $7.2 \mathrm{~g}$ of 6-acetamidohexanoic acid (the primary acetylation product of nylon 6), was mixed with $0.09 \mathrm{~g}$ cobalt(ous) acetate and $75 \mathrm{~mL}$ of $0.75 \mathrm{M}$ sulfuric acid. Square 1-inch platinum foil electrodes were used. The cell was stirred during the electrolysis, the current held constant at $480 \mathrm{~mA}$ with an average cell voltage of $2.9 \mathrm{~V}$. By GC-MS, the yield was found to be $70 \%$ adipic acid, with the rest being unreacted 6-acetamidohexanoic acid.

The successful oxidation to adipic acid represents a promising start, but there is still a long way to go before electrochemical methods can be easily used to break down carpet. In existing methods, pre-processing of the carpets (in the example shown, breaking down nylon into 6-acetamidohexanoic acid before proceeding with the method) is necessary, which can drastically increase the cost of a given process. Additionally, caprolactam is often the desired product of nylon recycling, and there are still no electrochemical means to produce it via electrochemical means.

4.1.6 Polyethylene terephthalate. Despite being one of the most produced plastics, PET is still recycled at low rates compared to its rates of production and use. ${ }^{134}$ Chemical methods for the recycling of PET require high temperatures of $120-180^{\circ} \mathrm{C}$ and utilize corrosive bases. ${ }^{135,136}$ Recent work by Myren and coworkers, however, reports the chemical hydrolysis of end-use PET at relatively low temperatures in chemical and microwave reactors in mixed aqueous/methanol media. ${ }^{133}$ The depolymerization of PET at room temperature through an electrochemical process is also reported. The breakdown of the ubiquitous ester-polymer is induced by base generated cathodically in situ in protic media as shown in 


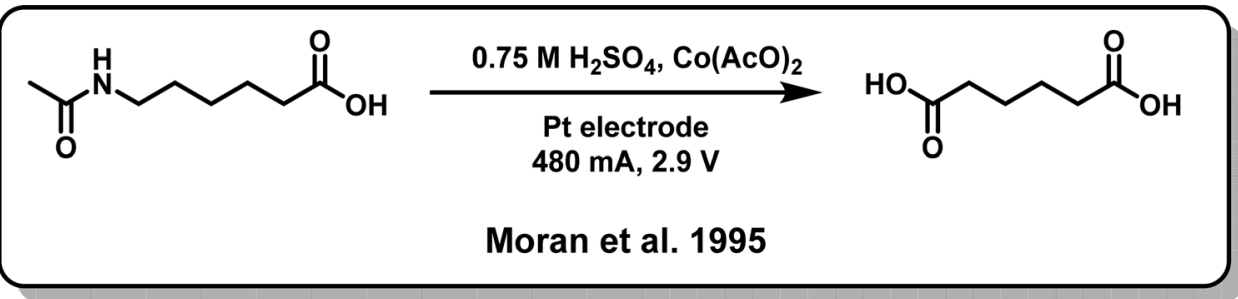

Fig. 14 Conversion of 6 -acetamidohexanoic acid to adipic acid as demonstrated by Moran et al. ${ }^{132}$

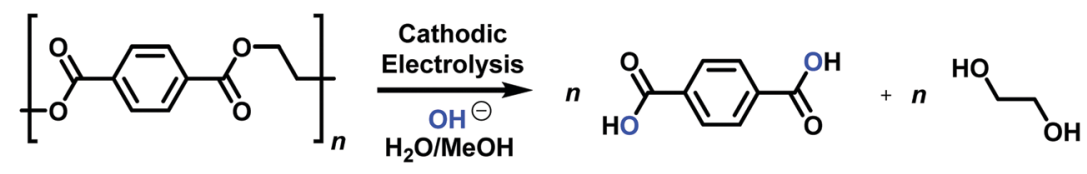

Myren et al. 2020

Fig. 15 Cathodic electrolytic depolymerization of PET through base-induced ester hydrolysis. ${ }^{133}$

Fig. 15. To the best of our knowledge this is the first instance of mechanistically-driven electrochemical reaction development for the depolymerization of end-use polymers and also the first example of electrochemical methodology targeting esters, setting the stage for exciting new technologies.

\subsection{Outlook on chemical vs. electrochemical techniques of polymer waste valorization}

The recycling of polymeric plastic waste with traditional mechanical methods causes the downgrading of the polymer quality and does not allow for the regeneration of a material with the original properties. This circumstance sustains a continuous need to use new feedstocks to produce virgin monomeric materials. The persistent production of petroleum-sourced virgin monomers and the consequent non-circular production of plastics trigger deleterious environmental effects and resource limitations.

Significant efforts are being invested in the development of new, biodegradable, recyclable polymers. However, the current scale of production of organic materials requires attention towards sustainable methods for recovery of valuable materials from waste already accumulated in the environment. These methods, in effect, mine valuable organics from waste streams that would otherwise be destined for landfills. Electrochemical methods targeting the selective cleavage of chemical bonds in complex structures and recovery of monomeric materials, or valuable derivatives thereof, therefore enable circularity of the polymer synthesis/use/recovery process. We remain forward looking to new developments in this research arena.

\section{Conclusions}

In summary, electrochemical methods are emerging as solutions to societal challenges related to resource limitations and accumulation of waste in landfills and the environment. The electrochemical recovery of metallic CRMs is a mature science, with several electrotechniques being deployed on scale. The accumulation of solid waste in the environment is now occurring against the backdrop of a linear take-make-waste economy and is exacerbated by the global pandemic. The electrochemical techniques depicted herein are now slowly emerging as solutions for "mining" organic materials form discarded wastes. While still in its infancy, the field of organic electrochemistry for materials recycling is blossoming due to renewed interest in recycling technologies and pressing environmental needs, enabling the circular economy and diversion of waste streams from landfills. In the long term, we foresee electrochemical methods as an answer to multi-step, CRM and organic materials recovery from complex, mixed materials.

\section{Conflicts of interest}

No conflicts of interest to declare.

\section{Acknowledgements}

ORL and the group would like to thank CU Boulder for startup funds. We would like to thank the reviewers for their time and expert suggestions. We thank the University of Colorado Boulder for startup funds.

\section{Notes and references}

1 A Linear Take-Make-Waste Economy Has Prevailed For The Last 50 Years, But The Circular Economy Is Where Value Will Be Created In The 21st Century, https://www.close dlooppartners.com/a-linear-take-make-waste-economy-hasprevailed-for-the-last-50-years-but-the-circular-economy-iswhere-value-will-be-created-in-the-21st-century/, accessed August 25, 2020. 
2 Why we'll still need waste in a circular economy, https:// theconversation.com/why-well-still-need-waste-in-a-circulareconomy-136470.

3 Y. Liu, J. Chen, Z. Liu, H. Xu, Y. Zheng, J. Zhong, Q. Yang, H. Tian, Z. Shi, J. Yao and C. Xiong, Facile fabrication of Fe3O4 nanoparticle/carbon nanofiber aerogel from Fe-ion cross-linked cellulose nanofibrils as anode for lithium-ion battery with superhigh capacity, J. Alloys Compd., 2020, 829, 154541.

4 Advanced Manufacturing Technology Consortia (AMTech) Program, https:/www.nist.gov/oam/programs/advancedmanufacturing-technology-consortia-amtech-program, accessed September 2.

5 V. Sivaram, J. O. Dabiri and D. M. Hart, The need for continued innovation in solar, wind, and energy storage, Joule, 2018, 2(9), 1639-1642.

6 A. Q. Fenwick, J. M. Gregoire and O. R. Luca, Electrocatalytic reduction of nitrogen and carbon dioxide to chemical fuels: Challenges and opportunities for a solar fuel device, J. Photochem. Photobiol., B, 2015, 152, 47-57.

7 O. R. Luca, C. C. McCrory, N. F. Dalleska and C. A. Koval, The selective electrochemical conversion of preactivated $\mathrm{CO}_{2}$ to methane, J. Electrochem. Soc., 2015, 162(7), H473.

8 S. W. Sheehan, US Pat., 20190233952, 2019.

9 Opus 12, https://www.opus-12.com/, accessed September 2.

10 A. Kang, From $\mathrm{CO}_{2}$ To Vodka: Air Company Launches World's First Carbon-Negative Spirit, https:/www.forbes. com/sites/annakang/2020/08/31/from-co2-to-vodka-air-companylaunches-worlds-first-carbon-negative-spirit/\#10be4dc74f5a, accessed September 2.

11 Critical Materials Strategy, DOE, Ed. 2011.

12 Office of the Secretary, I., Final List of Critical Minerals 2018. Interior, D. o. t., Ed. 2018.

13 AFederal Strategy To Ensure Secure and Reliable Supplies of Critical Minerals. President, E. O. o. t., Ed. 2017.

14 Mineral Commodity Summaries 2020. USGS, Ed. 2020.

15 R. R. Srivastava, M.-S. Kim, J.-C. Lee, M. K. Jha and B.-S. Kim, Resource recycling of superalloys and hydrometallurgical challenges, J. Mater. Sci., 2014, 49(14), 4671-4686.

16 C. G. Anderson, The metallurgy of antimony, Chem. Erde, 2012, 72, 3-8.

17 W. Jin and Y. Zhang, Sustainable Electrochemical Extraction of Metal Resources from Waste Streams: From Removal to Recovery, ACS Sustainable Chem. Eng., 2020, 8(12), 4693-4707.

18 Z. Li, L. He, Z. Zhao, D. Wang and W. Xu, Recovery of lithium and manganese from scrap $\mathrm{LiMn}_{2} \mathrm{O}_{4}$ by slurry electrolysis, ACS Sustainable Chem. Eng., 2019, 16738-16746.

19 A. S. Ismail, Electrodeposition of aluminium-copper alloy from 1-butyl-1-methylpyrrolidinium bis(trifluoromethylsulfonyl) imide ionic liquid, Egypt. J. Pet., 2017, 61-65.

20 E. M. Garcia, J. S. Santos, E. C. Pereira and M. B. J. G. Freitas, Electrodeposition of cobalt from spent Li-ion battery cathodes by the electrochemistry quartz crystal microbalance technique, J. Power Sources, 2008, 185(1), 549-553.

21 H. M. Veit, T. R. Diehl, A. P. Salami, J. S. Rodrigues, A. M. Bernardes and J. A. S. Tenório, Utilization of magnetic and electrostatic separation in the recycling of printed circuit boards scrap, Waste Manage., 2005, 25(1), 67-74.

22 C. A. Basha, K. Ramanathan, R. Rajkumar, M. Mahalakshmi and P. S. Kumar, Management of Chromium Plating Rinsewater Using Electrochemical Ion Exchange, Ind. Eng. Chem. Res., 2008, 47(7), 2279-2286.

23 W. Jin, H. Du, S. Zheng and Y. Zhang, Electrochemical processes for the environmental remediation of toxic $\mathrm{Cr}(\mathrm{VI})$ : A review, Electrochim. Acta, 2016, 191, 1044-1055.

24 P. Gao, X. Chen, F. Shen and G. Chen, Removal of chromium(VI) from wastewater by combined electrocoagulation-electroflotation without a filter, Sep. Purif. Technol., 2005, 43(2), 117-123.

25 G. A. M. Ali, M. M. Yusoff, E. R. Shaaban and K. F. Chong, High performance $\mathrm{MnO}_{2}$ nanoflower supercapacitor electrode by electrochemical recycling of spent batteries, Ceram. Int., 2017, 43(11), 8440-8448.

26 L. W. Reaugh, American Manganese Inc. Pilot Plant Optimization Tests Further Increase Recycling Process Capacity, https://americanmanganeseinc.com/americanmanganese-inc-pilot-plant-optimization-tests-further-increaserecycling-process-capacity/.

27 J. H. Downing, Manganese Processing, https://www.britannica. com/technology/manganese-processing, accessed May 30.

28 L. W. Reaugh, American Manganese Inc. Announces Conceptual Commercial Recycling Plant Layout for Lithium-ion Battery Cathode Material, 2020.

29 S. Zein El Abedin, Electrochemical behavior of aluminum and some of its alloys in chloroaluminate ionic liquids: electrolytic extraction and electrorefining, J. Solid State Electrochem., 2012, 16(2), 775-783.

30 V. Kamavaram, D. Mantha and R. G. Reddy, Recycling of aluminum metal matrix composite using ionic liquids, Electrochim. Acta, 2005, 50(16-17), 3286-3295.

31 M. E. H. Bergmann and A. S. Koparal, Electrochemical antimony removal from accumulator acid: Results from removal trials in laboratory cells, J. Hazard. Mater., 2011, 196, 59-65.

$32 \mathrm{H}$. Singh and P. K. Jain, Remanufacturing with ECH - A Concept, Procedia Eng., 2014, 69, 1100-1104.

33 H. Singh and P. K. Jain, Electrochemical Honing of Mating Clad Surfaces - A Concept towards Remanufacturing Engineering, ICPME'2014, 2014.

34 D. Benyahia and R. Hausler, Study of Recovering and Separating the Waste Metal Layers Aircraft by Electrochemical Treatment, Int. J. Environ. Sci. Dev., 2016, 7(9), 668-671.

35 E. Rombach and B. Friedrich, Recycling of Rare Metals, in Handbook of Recycling, ed. E. Worrell and M. A. Reuter, Elsevier, Boston, 2014, ch. 10, pp. 125-150.

36 L. Kong, T. Ouchi, C. Zheng and T. H. Okabe, Electrochemical Deoxidation of Titanium Scrap in $\mathrm{MgCl}_{2}-\mathrm{HoCl}_{3}$ System, J. Electrochem. Soc., 2019, 166(13), E429.

37 Y. Song and Z. Zhao, Recovery of lithium from spent lithium-ion batteries using precipitation and electrodialysis techniques, Sep. Purif. Technol., 2018, 206, 335-342.

38 M. B. J. G. Freitas and E. M. Garcia, Electrochemical recycling of cobalt from cathodes of spent lithium-ion batteries, J. Power Sources, 2007, 171(2), 953-959. 
39 C. Lupi, M. Pasquali and A. Dell'Era, Nickel and cobalt recycling from lithium-ion batteries by electrochemical processes, Waste Manage., 2005, 25(2), 215-220.

40 P.-S. Pa, Environmentally friendly electrochemical recycling of indium from scrap ITO glass and PET, Int. J. Adv. Manuf. Technol., 2017, 89(5-8), 1295-1306.

41 A. M. K. Gustafsson, F. Björefors, B.-M. Steenari and C. Ekberg, Investigation of an Electrochemical Method for Separation of Copper, Indium, and Gallium from Pretreated CIGS Solar Cell Waste Materials, Sci. World J., 2015, 2015, 1-11.

42 M. L. C. M. Henckens, P. P. J. Driessen and E. Worrell, Metal scarcity and sustainability, analyzing the necessity to reduce the extraction of scarce metals, Resour., Conserv. Recycl., 2014, 93, 1-8.

43 S. M. Fortier, N. T. Nassar, G. W. Lederer, J. Brainard, J. Gambogi and E. A. McCullough, Draft critical mineral list-Summary of methodology and background informationU.S. Geological Survey technical input document in response to Secretarial Order No. 3359, 2018-1021, Reston, VA, 2018, p. 26.

44 G. Belardi, R. Lavecchia, F. Medici and L. Piga, Thermal treatment for recovery of manganese and zinc from zinccarbon and alkaline spent batteries, Waste Manage., 2012, 32(10), 1945-1951.

45 H. Mekhalfi, N. Chelali, S. Benhamimid, O. M. Laib, B. Nessark and A. Bahloul, Recycling of manganese dioxide from spent Zn-MnO2 cells, Russ. J. Appl. Chem., 2015, 88(5), 879-884.

46 J. Nan, D. Han, M. Cui, M. Yang and L. Pan, Recycling spent zinc manganese dioxide batteries through synthesizing Zn-Mn ferrite magnetic materials, J. Hazard. Mater., 2006, 133(1-3), 257-261.

47 M. B. J. G. Freitas, V. C. Pegoretti and M. K. Pietre, Recycling manganese from spent $\mathrm{Zn}-\mathrm{MnO} 2$ primary batteries, J. Power Sources, 2007, 164(2), 947-952.

48 V. E. O. Santos, V. G. Celante, M. F. F. Lelis and M. B. J. G. Freitas, Chemical and electrochemical recycling of the nickel, cobalt, zinc and manganese from the positives electrodes of spent Ni-MH batteries from mobile phones, J. Power Sources, 2012, 218, 435-444.

49 A. T. Tabereaux and R. D. Peterson, Aluminum Production, Elsevier, 2014, pp. 839-917.

50 B. J. Welch and R. A. Osteryoung, Electrochemical studies in low temperature molten salt systems containing alumnium chloride, J. Electroanal. Chem. Interfacial Electrochem., 1981, 118, 455-466.

51 P. Giridhar, S. Zein El Abedin and F. Endres, Electrodeposition of nanocrystalline aluminium, copper, and copper-aluminium alloys from 1-butyl-1-methylpyrrolidinium trifluoromethylsulfonate ionic liquid, J. Solid State Electrochem., 2012, 16(11), 3487-3497.

52 X. Yi, Y. Qi, F. Li, J. Shu, Z. Sun, S. Sun, M. Chen and S. Pu, Effect of electrolyte reuse on metal recovery from waste CPU slots by slurry electrolysis, Waste Manage., 2019, 95, 370-376.

53 R. G. Cooper and A. P. Harrison, The exposure to and health effects of antimony, Indian J. Occup. Environ. Med., 2009, 13(1), 3-10.
54 S.-Y. Tan, D. J. Payne, J. P. Hallett and G. H. Kelsall, Developments in electrochemical processes for recycling lead-acid batteries, Curr. Opin. Electrochem., 2019, 16, 83-89.

55 K. Ramus and P. Hawkins, Lead/acid battery recycling and the new Isasmelt process, J. Power Sources, 1993, 42(1-2), 299-313.

56 A. D. Besser, V. S. Sorokina, O. K. Sokolov and V. M. Paretskii, Processing of utilized lead-acid storage batteries-The basis of lead recycling, Russ. Metall., 2009, 2009(8), 781-787.

57 G. F. Werner and R. J. Massonne, Process for the recovery of antimony pentachloride from used catalyst solutions, US Pat., 4070439, 1977.

58 D. E. Hyatt, Recovery of Arsenic and Antimony from Spent Antimony Catalyst, US Pat., US4722774A, 1988.

59 V. V. Turygin, M. K. Smirnov, A. V. Smetanin, E. G. Zhukov, V. A. Fedorov and A. P. Tomilov, Electrochemical arsenic extraction from nonferrous metals industry waste, Inorg. Mater., 2008, 44(9), 946-953.

60 N. Kongsricharoern and C. Polprasert, Electrochemical precipitation of chromium $\left(\mathrm{Cr}^{6+}\right)$ from an electroplating wastewater, Water Sci. Technol., 1995, 31(9), 109-117.

61 N. Kongsricharoern and C. Polprasert, Chromium Removal by a Bipolar Electro-Chemical Precipitation Process, Water Sci. Technol., 1996, 34(9), 109-116.

62 Y. Zhang, Q. Li, R. Tang, Q. Hu, L. Sun and J. Zhai, Electrocatalytic reduction of chromium by poly(anilineco-o-aminophenol): An efficient and recyclable way to remove $\mathrm{Cr}(\mathrm{VI})$ in wastewater, Appl. Catal., B, 2009, 92(34), 351-356.

63 E. M. Garcia, H. A. Tarôco, T. Matencio, R. Z. Domingues, J. A. F. Dos Santos and M. B. J. G. De Freitas, Electrochemical recycling of cobalt from spent cathodes of lithium-ion batteries: its application as coating on SOFC interconnects, J. Appl. Electrochem., 2011, 41(11), 1373-1379.

64 E. M. Garcia, H. A. Tarôco, T. Matencio, R. Z. Domingues, J. A. F. Dos Santos, R. V. Ferreira, E. Lorençon, D. Q. Lima and M. B. J. G. De Freitas, Electrochemical recycling of cobalt from spent cathodes of lithium-ion batteries: its application as supercapacitor, J. Appl. Electrochem., 2012, 42(6), 361-366.

65 Encyclopedia of Electrochemical Power Sources, ed. J. Garche, Elsevier, 2009.

66 J. L. Sullivan and L. Gaines, Status of life cycle inventories for batteries, Energy Convers. Manage., 2012, 58, 134-148.

67 L. Pietrelli, B. Bellomo, D. Fontana and M. Montereali, Characterization and leaching of NiCd and NiMH spent batteries for the recovery of metals, J. Waste Manage., 2005, 25(2), 221-226.

68 D. Choi, Y. S. Kim and Y. Son, Recovery of indium tin oxide (ITO) and glass plate from discarded TFT-LCD panels using an electrochemical method and acid treatment, RSC Adv., 2014, 4(92), 50975-50980.

69 P. F. C. Britt, W. Geoffrey, K. I. Winey, J. Byers, E. Chen, B. Coughlin, C. Ellison, J. Garcia, A. Goldman, J. Guzman, J. Hartwig, B. Helms, G. Huber, C. Jenks, J. Martin, M. McCann, S. Miller, H. O'Neill, A. Sadow, S. Scott, 
L. Sita, D. Vlachos and R. Waymouth, Report of the Basic Energy Sciences Roundtable on Chemical Upcycling of Polymers; United States Department of Energy Office of Science, Bethesda, Maryland, 2019.

70 Advancing Sustainable Materials Management: 2017 Fact Sheet, United States Environmental Protection Agency, 2019.

71 A. Rahimi and J. M. García, Chemical recycling of waste plastics for new materials production, Nat. Rev. Chem., 2017, 1(6), 0046.

72 J. Zakzeski, P. C. A. Bruijnincx, A. L. Jongerius and B. M. Weckhuysen, The Catalytic Valorization of Lignin for the Production of Renewable Chemicals, Chem. Rev., 2010, 110(6), 3552-3599.

73 M. Dębowski, A. Iuliano, A. Plichta, S. Kowalczyk and Z. Florjańczyk, Chemical recycling of polyesters, Polimery, 2019, 64(11-12), 764-776.

74 O. R. Luca, J. L. Gustafson, S. M. Maddox, A. Q. Fenwick and D. C. Smith, Catalysis by electrons and holes: formal potential scales and preparative organic electrochemistry, Org. Chem. Front., 2015, 2(7), 823-848.

75 A. Pinkert, K. N. Marsh, S. Pang and M. P. Staiger, Ionic Liquids and Their Interaction with Cellulose, Chem. Rev., 2009, 109(12), 6712-6728.

76 L. S. Sobhanadhas, L. Kesavan and P. Fardim, Topochemical Engineering of Cellulose-Based Functional Materials, Langmuir, 2018, 34(34), 9857-9878.

77 S. Li, Z. Cheng, T. Xie, Z. Dong and G. Liu, CelluloseDerived Carbon Microfiber Mesh for Binder-Free LithiumSulfur Batteries, J. Nanosci. Nanotechnol., 2020, 20(9), 5629-5635.

78 D. Meng, G. Li, Z. Liu and F. Yang, Study of depolymerization of cotton cellulose by $\mathrm{Pb} / \mathrm{PbO}_{2}$ anode electrochemical catalysis in sulfuric acid solution, Polym. Degrad. Stab., 2011, 96(7), 1173-1178.

79 A. S. Amarasekara and C. C. Ebede, Zinc chloride mediated degradation of cellulose at $200{ }^{\circ} \mathrm{C}$ and identification of the products, Bioresour. Technol., 2009, 100(21), 5301-5304.

80 J.-H. Lin, Y.-H. Chang and Y.-H. Hsu, Degradation of cotton cellulose treated with hydrochloric acid either in water or in ethanol, Food Hydrocolloids, 2009, 23(6), 1548-1553.

81 T. Deng, J. Sun and H. Liu, Cellulose conversion to polyols on supported Ru catalysts in aqueous basic solution, Sci. China: Chem., 2010, 53(7), 1476-1480.

82 J. Wan, J. Zhang, J. Yu and J. Zhang, Cellulose Aerogel Membranes with a Tunable Nanoporous Network as a Matrix of Gel Polymer Electrolytes for Safer Lithium-Ion Batteries, ACS Appl. Mater. Interfaces, 2017, 9(29), 24591-24599.

83 O. Senneca, F. Cerciello, C. Russo, A. Wütscher, M. Muhler and B. Apicella, Thermal treatment of lignin, cellulose and hemicellulose in nitrogen and carbon dioxide, Fuel, 2020, 271, 117656.

84 F. Gu and $\mathrm{H}$. Liu, Hydroxyl radicals-mediated oxidative cleavage of the glycosidic bond in cellobiose by copper catalysts and its application to low-temperature depolymerization of cellulose, Chin. J. Catal., 2020, 41(7), 1073-1080.
85 T. Isogai, T. Saito and A. Isogai, TEMPO Electromediated Oxidation of Some Polysaccharides Including Regenerated Cellulose Fiber, Biomacromolecules, 2010, 11(6), 1593-1599.

86 H. Zhu, L. Wang, Y. Chen, G. Li, H. Li, Y. Tang and P. Wan, Electrochemical depolymerization of lignin into renewable aromatic compounds in a non-diaphragm electrolytic cell, RSC Adv., 2014, 4(56), 29917.

87 R. Font, M. Esperanza and A. Nuria García, Toxic by-products from the combustion of Kraft lignin, Chemosphere, 2003, 52(6), 1047-1058.

88 M. A. Amezcua-Allieri and J. Aburto, Conversion of Lignin to Heat and Power, Chemicals or Fuels into the Transition Energy Strategy, in Lignin - Trends and Applications, ed. M. Poletto, InTech, 2018.

89 J. D. Garguiak and S. E. Lebo, Commercial Use of LigninBased Materials, in Lignin: Historical, Biological, and Materials Perspectives, American Chemical Society, 1999, vol. 742, pp. 304-320.

90 Y. Polat, E. Stojanovska, T. A. Negawo, E. Doner and A. Kilic, Lignin as an Additive for Advanced Composites, in Green Biocomposites: Manufacturing and Properties, ed. M. Jawaid, S. M. Sapuan and O. Y. Alothman, Springer International Publishing, Cham, 2017, pp. 71-89.

91 H. Jensen, Fired Up by Lignin, Ethanol Producer Magazine, 2015. 92 T. Radoykova, S. Nenkova and K. Stanulov, Production of phenol compounds by alkaline treatment of poplar wood bark, Chem. Nat. Compd., 2010, 46(5), 807-808.

93 S. Constant, M. Robitzer, F. Quignard and F. Di Renzo, Vanillin oligomerization as a model of side reactions in lignin fragmentation, Catal. Today, 2012, 189(1), 123-128.

94 Q. Song, F. Wang, J. Cai, Y. Wang, J. Zhang, W. Yu and J. Xu, Lignin depolymerization (LDP) in alcohol over nickel-based catalysts via a fragmentation-hydrogenolysis process, Energy Environ. Sci., 2013, 6(3), 994-1007.

95 T. Renders, G. Van den Bossche, T. Vangeel, K. Van Aelst and B. Sels, Reductive catalytic fractionation: state of the art of the lignin-first biorefinery, Curr. Opin. Biotechnol., 2019, 56, 193-201.

96 W. Schutyser, A. T. Renders, S. Van den Bosch, S.-F. Koelewijn, G. Beckham and B. F. Sels, Chemicals from lignin: an interplay of lignocellulose fractionation, depolymerisation, and upgrading, Chem. Soc. Rev., 2018, 47(3), 852-908.

97 C. Li, M. Zheng, A. Wang and T. Zhang, One-pot catalytic hydrocracking of raw woody biomass into chemicals over supported carbide catalysts: simultaneous conversion of cellulose, hemicellulose and lignin, Energy Environ. Sci., 2012, 5(4), 6383-6390.

98 N. Yan, C. Zhao, P. J. Dyson, C. Wang, L. T. Liu and Y. Kou, Selective degradation of wood lignin over noble-metal catalysts in a two-step process, ChemSusChem, 2008, 1(7), 626-629.

99 A. L. Jongerius, R. Jastrzebski, P. C. Bruijnincx and B. M. Weckhuysen, CoMo sulfide-catalyzed hydrodeoxygenation of lignin model compounds: An extended reaction network for the conversion of monomeric and dimeric substrates, J. Catal., 2012, 285(1), 315-323. 
100 D. Di Marino, T. Jestel, C. Marks, J. Viell, M. Blindert, S. M. A. Kriescher, A. C. Spiess and M. Wessling, Carboxylic Acids Production via Electrochemical Depolymerizationof Lignin, ChemElectroChem, 2019, 6, 1434-1442.

101 B. Bawareth, D. Di Marino, T. A. Nijhuis and M. Wessling, Unravelling Electrochemical Lignin Depolymerization, ACS Sustainable Chem. Eng., 2018, 6(6), 7565-7573.

102 S. Stiefel, A. Schmitz, J. Peters, D. Di Marino and M. Wessling, An integrated electrochemical process to convert lignin to value-added products under mild conditions, Green Chem., 2016, 18(18), 4999-5007.

103 T. K. F. Dier, D. Rauber, D. Durneata, R. Hempelmann and D. A. Volmer, Sustainable Electrochemical Depolymerization of Lignin in Reusable Ionic Liquids, Sci. Rep., 2017, 7(1), 5041.

104 D. Schmitt, C. Regenbrecht, M. Hartmer, F. Stecker and S. R. Waldvogel, Highly selective generation of vanillin by anodic degradation of lignin: a combined approach of electrochemistry and product isolation by adsorption, Beilstein J. Org. Chem., 2015, 11, 473-480.

105 C. Li, X. Zhao, A. Wang, G. W. Huber and T. Zhang, Catalytic Transformation of Lignin for the Production of Chemicals and Fuels, Chem. Rev., 2015, 115(21), 11559-11624.

106 G. Chatel and R. D. Rogers, Review: Oxidation of Lignin Using Ionic Liquids-An Innovative Strategy To Produce Renewable Chemicals, ACS Sustainable Chem. Eng., 2014, 2(3), 322-339.

107 I. Bosque, G. Magallanes, M. Rigoulet, M. D. Kärkäs and C. R. J. Stephenson, Redox Catalysis Facilitates Lignin Depolymerization, ACS Cent. Sci., 2017, 3(6), 621-628.

108 H. Zhu, Z. Peng, Y. Chen, G. Li, L. Wang, Y. Tang, R. Pang, Z. U. H. Khan and P. Wan, Preparation and characterization of flame retardant polyurethane foams containing phosphorusnitrogen-functionalized lignin, $R S C A d v$., 2014, 4(98), 55271-55279.

109 S. K. Shukla, A. K. Mishra, O. A. Arotiba and B. B. Mamba, Chitosan-based nanomaterials: A state-of-the-art review, Int. J. Biol. Macromol., 2013, 59, 46-58.

110 F. Shahidi and J. Synowiecki, Isolation and characterization of nutrients and value-added products from snow crab (Chionoecetes opilio) and shrimp (Pandalus borealis) processing discards, J. Agric. Food Chem., 1991, 39(8), 1527-1532.

111 N. Yan and X. Chen, Sustainability: Don't waste seafood waste, Nature, 2015, 524, 155-157.

112 The State of World Fisheries and Aquaculture Food and Agriculture Organization of the United Nations: Rome, 2014.

113 M. B. Kaczmarek, K. Struszczyk-Swita, X. Li, M. SzczęsnaAntczak and M. Daroch, Enzymatic Modifications of Chitin, Chitosan, and Chitooligosaccharides, Front. Bioeng. Biotechnol., 2019, 7, 243.

114 L. Deng, M. Taxipalati, A. Zhang, F. Que, H. Wei, F. Feng and H. Zhang, Electrospun Chitosan/Poly(ethylene oxide)/ Lauric Arginate Nanofibrous Film with Enhanced Antimicrobial Activity, J. Agric. Food Chem., 2018, 66(24), 6219-6226.

115 H. Liu, J. Bao, Y. Du, X. Zhou and J. F. Kennedy, Effect of ultrasonic treatment on the biochemphysical properties of chitosan, Carbohydr. Polym., 2006, 64(4), 553-559.
116 S. X. Tiew and M. Misran, Encapsulation of salicylic acid in acylated low molecular weight chitosan for sustained release topical application, J. Appl. Polym. Sci., 2017, 134(36), 44849.

117 Z. Gu, Q. Cai, Y. Liu and F. Li, Electrochemical Degradation of Chitosan Using Ti/Sb-SnO 2 Electrode, J. Polym. Environ., 2013, 21(2), 479-486.

118 Q. Cai, Z. Gu, Y. Chen, W. Han, T. Fu, H. Song and F. Li, Degradation of chitosan by an electrochemical process, Carbohydr. Polym., 2010, 79(3), 783-785.

119 W.-B. Luo, Z. Han, X.-A. Zeng, S.-J. Yu and J. F. Kennedy, Study on the degradation of chitosan by pulsed electric fields treatment, Innovative Food Sci. Emerging Technol., 2010, 11(4), 587-591.

120 F. Ma, P. Li, B. Zhang and Z. Wang, The facile synthesis of a chitosan $\mathrm{Cu}$ (II) complex by solution plasma process and evaluation of their antioxidant activities, Int. J. Biol. Macromol., 2017, 103, 501-507.

121 F. Ma, Z. Wang, H. Zhao and S. Tian, Plasma depolymerization of chitosan in the presence of hydrogen peroxide, Int. J. Mol. Sci., 2012, 13(6), 7788-7797.

122 K. Naima and A. Liazid, Waste oils as alternative fuel for diesel engine: A review, J. Pet. Technol. Altern. Fuels, 2013, 4(3), 30-43.

123 D. Jubinville, E. Esmizadeh, S. Saikrishnan, C. Tzoganakis and T. Mekonnen, A comprehensive review on global production and recycling methods of polyolefin (PO) based products and their post-recycling applications, Sustainable Mater. Technol., 2020, e00188.

124 J. Gong, J. Liu, X. Wen, Z. Jiang, X. Chen, E. Mijowska and T. Tang, Upcycling waste polypropylene into graphene flakes on organically modified montmorillonite, Ind. Eng. Chem. Res., 2014, 53(11), 4173-4181.

125 Z. Zhang, L. Liao, Z. Xia and C. Li, Montmorillonite-carbon nanocomposites with nanosheet and nanotube structure: Preparation, characterization and structure evolution, Appl. Clay Sci., 2012, 55, 75-82.

126 C. Yan, J. Wang, H. Du, L. Zhu, T. Jiang, H. Jiang, H. Wu and B. Wang, Solar Thermal Electrochemical Process (STEP) action to biomass: Solar thermo-coupled electrochemical synergy for efficient breaking of biomass to biofuels and hydrogen, Energy Convers. Manage., 2019, 180, 1247-1259.

127 P. Dwivedi, P. K. Mishra, M. K. Mondal and N. Srivastava, Non-biodegradable polymeric waste pyrolysis for energy recovery, Heliyon, 2019, 5(8), e02198.

128 R. Miandad, M. Rehan, M. A. Barakat, A. S. Aburiazaiza, H. Khan, I. M. I. Ismail, J. Dhavamani, J. Gardy, A. Hassanpour and A.-S. Nizami, Catalytic Pyrolysis of Plastic Waste: Moving Toward Pyrolysis Based Biorefineries, Front. Energy Res., 2019, $7,27$.

129 T. Jiang, X. Zhao, D. Gu, C. Yan, H. Jiang, H. Wu, B. Wang and X. Wang, STEP polymer degradation: Solar thermocoupled electrochemical depolymerization of plastics to generate useful fuel plus abundant hydrogen, Sol. Energy Mater. Sol. Cells, 2020, 204, 110208.

130 F. Lv, D. Yao, Y. Wang, C. Wang, P. Zhu and Y. Hong, Recycling of waste nylon 6/spandex blended 
fabrics by melt processing, Composites, Part B, 2015, 77, 232-237.

131 C. Mihut, D. K. Captain, F. Gadala-Maria and M. D. Amiridis, Review: Recycling of nylon from carpet waste, Polym. Eng. Sci., 2001, 41(9), 1457-1470.

132 E. F. Moran and R. J. McKinney, Conversion of Nylon 6 and/ or Nylon 6,6 to Adipic Acid, 1995.

133 T. H. Myren, T. A. Stinson, Z. J. Mast, C. G. Huntzinger and O. R. Luca, Chemical and Electrochemical Recycling of End-Use Poly (ethylene Terephthalate)(PET) Plastics in
Batch, Microwave and Electrochemical Reactors, Molecules, 2020, 25(12), 2742.

134 B. Kuczenski and R. Geyer, Material flow analysis of polyethylene terephthalate in the US, 1996-2007, Resour., Conserv. Recycl., 2010, 54(12), 1161-1169.

135 K. Marsh and B. Bugusu, Food packaging-roles, materials, and environmental issues, J. Food Sci., 2007, 72(3), R39-R55.

136 C. Jehanno, M. M. Pérez-Madrigal, J. Demarteau, H. Sardon and A. P. Dove, Organocatalysis for depolymerisation, Polym. Chem., 2019, 10(2), 172-186. 